\title{
Mechanism of efficient anti-Markovnikov olefin hydroarylation catalyzed by homogeneous Ir(III) complexes $\uparrow$
}

\author{
Gaurav Bhalla, ${ }^{a}$ Steven M. Bischof, ${ }^{b}$ Somesh K. Ganesh, ${ }^{a, b}$ Xiang Yang Liu, ${ }^{a}$ C. J. Jones, ${ }^{a}$ \\ Andrey Borzenko, ${ }^{a}$ William J. Tenn, III, ${ }^{a}$ Daniel H. Ess, ${ }^{b, c}$ Brian G. Hashiguchi, ${ }^{b}$ Kapil S. Lokare, ${ }^{b}$ \\ Chin Hin Leung, ${ }^{b}$ Jonas Oxgaard, ${ }^{c}$ William A. Goddard, III*c and Roy A. Periana ${ }^{* a, b}$
}

Received 15th July 2010, Accepted 28th October 2010

DOI: 10.1039/c0gc00330a

The mechanism of the hydroarylation reaction between unactivated olefins (ethylene, propylene, and styrene) and benzene catalyzed by $\left[(\mathrm{R}) \operatorname{Ir}\left(\mu \text {-acac- } O, O, \mathrm{C}^{3}\right)-(\text { acac- } O, O)_{2}\right]_{2}$ and $\left[\mathrm{R}-\mathrm{Ir}(\text { acac- } \mathrm{O}, \mathrm{O})_{2}(\mathrm{~L})\right]\left(\mathrm{R}=\right.$ acetylacetonato, $\mathrm{CH}_{3}, \mathrm{CH}_{2} \mathrm{CH}_{3}, \mathrm{Ph}$, or $\mathrm{CH}_{2} \mathrm{CH}_{2} \mathrm{Ph}$, and $\mathrm{L}=\mathrm{H}_{2} \mathrm{O}$ or pyridine) $\mathrm{Ir}$ (III) complexes was studied by experimental methods. The system is selective for generating the anti-Markovnikov product of linear alkylarenes $(61: 39$ for benzene + propylene and $98: 2$ for benzene + styrene). The reaction mechanism was found to follow a rate law with first-order dependence on benzene and catalyst, but a non-linear dependence on olefin.

${ }^{13} \mathrm{C}$-labelling studies with $\mathbf{C H}_{3}{ }^{13} \mathbf{C H}_{2}$-Ir-Py showed that reversible $\beta$-hydride elimination is facile, but unproductive, giving exclusively saturated alkylarene products. The migration of the ${ }^{13} \mathrm{C}$-label from the $\alpha$ to $\beta$-positions was found to be slower than the $\mathrm{C}-\mathrm{H}$ activation of benzene (and thus formation of ethane and $\mathbf{P h}-\mathbf{d}_{\mathbf{5}}-\mathbf{I r}-\mathbf{P y}$ ). Kinetic analysis under steady state conditions gave a ratio of the rate constants for $\mathrm{CH}$ activation and $\beta$-hydride elimination $\left(k_{\mathrm{CH}}: k_{\beta}\right)$ of $\sim 0.5$. The

comparable magnitude of these rates suggests a common rate determining transition state/intermediate, which has been shown previously with B3LYP density functional theory (DFT) calculations. Overall, the mechanism of hydroarylation proceeds through a series of pre-equilibrium dissociative steps involving rupture of the dinuclear species or the loss of $\mathrm{L}$ from $\mathbf{P h}$-Ir-L to the solvento, 16-electron species, $\mathbf{P h}-\mathbf{I r}(\mathbf{a c a c}-\boldsymbol{O}, \mathbf{O})_{2}$-Sol (where Sol refers to coordinated solvent). This species then undergoes trans to cis isomerization of the acetylacetonato ligand to yield the pseudo octahedral species cis-Ph-Ir-Sol, which is followed by olefin insertion (the regioselective and rate determining step), and then activation of the $\mathrm{C}-\mathrm{H}$ bond of an incoming benzene to generate the product and regenerate the catalyst.

\section{Introduction}

The coupling reaction of arenes and olefins to generate alkylarenes continues to be both an important $\mathrm{C}-\mathrm{C}$ bond forming reaction and route to functionalize $\mathrm{C}-\mathrm{H}$ bonds. ${ }^{1}$ Classically, straight-chain and branched-chain alkylbenzenes are generated by a Friedel-Crafts acylation followed by reduction or electrophilic substitution of an arene (Scheme 1a and c, respectively). ${ }^{2}$ This requires the use of halogenated hydrocarbon

${ }^{a}$ The Loker Hydrocarbon Institute, Department of Chemistry, University of Southern California, Los Angeles, California, 90089.

${ }^{b}$ The Scripps Energy Laboratories, Department of Chemistry, The Scripps Research Institute, Jupiter, Florida, 33458, USA.

E-mail: rperiana@scripps.edu

'Materials and Process Simulation Center, Division of Chemistry and Chemical Engineering, California Institute of Technology, Pasadena,

California,91125.E-mail: wag@wag.caltech.edu

$\dagger$ Electronic supplementary information (ESI) available: Kinetic experiments. See DOI: $10.1039 / \mathrm{c} 0 \mathrm{gc} 00330 \mathrm{a}$ starting materials and several additional synthetic steps both of which generate excessive and hazardous halogenated waste. In addition, regioselectivity in these reactions is often difficult to predict and control because it is determined by the stability of the carbocation intermediate. ${ }^{3}$ Therefore, development of alternative catalysts not based on obligatory carbocation intermediates that control regio- and stereoselectivity with tolerance to a broad range of substrates and functional groups would be advantageous. This suggests that strategies based on using the $\mathrm{C}-\mathrm{H}$ bond activation reaction ${ }^{4}$ followed by selective $\mathrm{C}-\mathrm{C}$ bond functionalization (Scheme 1b) would minimize halogenated waste and unnecessary multistep procedures while still allowing access to these useful functionalized products.

The most practical approach to generate the formal Markovnikov (branched) hydroarylation addition was developed by Murai and co-workers using chelation-assistance to directly react olefins with acylheteroaromatics catalyzed by $\mathrm{Ru}{ }^{5}$ Due to the availability of a coordinating $\mathrm{N}$ or $\mathrm{O}$, it is believed these systems operate via chelation assisted $\mathrm{C}-\mathrm{H}$ activation 


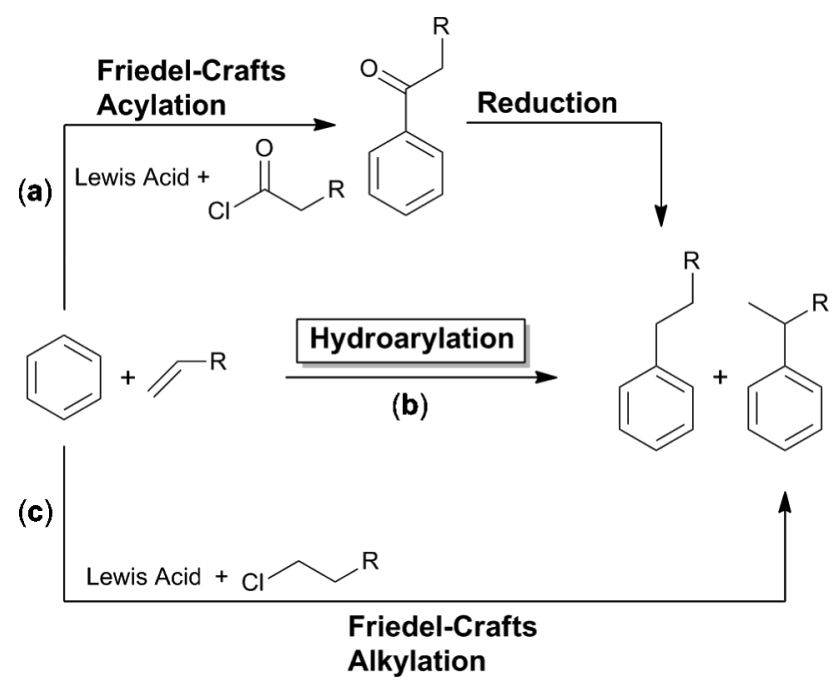

Scheme 1 Comparison of (a) Friedel-Crafts acylation followed by Clemmenson reduction, (b) hydroarylation of olefins, and (c) FriedelCrafts alkylation.

by initial coordination of the $\mathrm{N}$ or $\mathrm{O}$ group followed by directed intramolecular $\mathrm{C}-\mathrm{H}$ activation. More recently, similar O-atom chelation assistance was observed using $\mathrm{Re}, \mathrm{Rh}$, and $\mathrm{Au}$ complexes. ${ }^{6}$ The Goldman group has shown that $\operatorname{Ir}(\mathrm{PCP})$ pincer complexes selectively add the ortho $\mathrm{C}-\mathrm{H}$ bonds of nitrobenzene and acetophenone to olefins; however this was found to be the result of thermodynamic control and not chelation assistance. ${ }^{7}$ Other groups have utilized intramolecular reactions with alkenes tethered to aryl substrates to facilitate a ring-closing hydroarylation reaction. ${ }^{8}$ Currently, Markovnikov hydroarylation catalytic systems have been limited to metals such as $\mathrm{Pt}, \mathrm{Pd}, \mathrm{Ir}, \mathrm{Au}$, and $\mathrm{Ru}{ }^{9}$

There are limitations to the route developed by Murai and Goldman because they yield only the branched (Markovnikov) products, and access to the linear (antiMarkovnikov) products are vital to a synthetic toolbox. In addition, conventional techniques (Scheme 1a or c) require the use of multi-step processes that produce large quantities of halogen-containing waste. More recently, we and others have developed a variety of systems based on $\mathrm{Ru}, \mathrm{Rh}, \mathrm{Ir}$, and $\mathrm{Pt}$ that generate the preferred anti-Markovnikov selectivity in a single step reaction. ${ }^{10}$

Computational studies of such systems have revealed a delicate balance between the two steps of hydroarylation: 1) olefin insertion into the coordinated Ir-phenyl and 2) $\mathrm{C}-\mathrm{H}$ activation of the arene. ${ }^{11}$ It was determined that these two steps often have an inverse relationship and the energy barrier for one step adversely affects the other. By studying several computational analogues of our bis-(acac- $O, O$ ) Ir motif and Gunnoe's $\mathrm{Tp}-\mathrm{Ru}(\mathrm{Ph})\left(\mathrm{CH}_{3} \mathrm{CN}\right)(\mathrm{CO})^{12}$ system (which reacts via the same mechanism), it was concluded that the barriers for $\mathrm{C}-$ $\mathrm{H}$ activation and olefin insertion are dependent on the energy of the metal d-orbitals. Thus, the barrier for olefin insertion increases with higher energy d-orbitals, while the barrier for C$\mathrm{H}$ activation correspondingly decreases. Similar computational studies were conducted with selected systems that favor antiMarkovnikov products to reveal that both sterically bulky and electron-deficient olefins appear to favor linear products. ${ }^{13}$
Whereas more electron-rich metal/ligand systems also yield higher linear/branch ratios. In addition, the effect of sterics versus electronics on the linear to branched ratio cannot be generalized and is dependent on each specific system.

The most practical approach for the generation of antiMarkovnikov hydroarylation products was initially reported by Periana, Matsumoto, and co-workers in 2000. ${ }^{14}$ The reaction entailed $\mathrm{C}-\mathrm{H}$ bond activation of benzene followed by olefin insertion to generate $\mathrm{C}-\mathrm{C}$ functionalized products with selectivity towards the straight chain alkylbenzene (Scheme 1b).

The hydroarylation reaction was catalyzed by an O-donor, dinuclear, Ir ${ }^{\text {III }}$ complex based on the bis-acac motif, [Acac- $C$ $\mathrm{Ir}]_{2}$. Throughout this paper, unless otherwise specified, acac- $O, O$ is the O-bound, acetylacetonato or 2,4-pentanedione ligand. To further simplify discussion, the four-coordinate (acac- $O, O)_{2} \mathrm{Ir}^{\mathrm{III}}$ motif is abbreviated as, Ir, and trans and cis refer to the orientation of the two non-spectator ligands on this motif. Thus, the abbreviation, trans-R-Ir-L, is understood to be the trans(acac- $O, O)_{2} \mathrm{Ir}^{\mathrm{III}}(\mathrm{L})(\mathrm{R})$ complex with the non-spectator ligands, $\mathrm{R}$ and $\mathrm{L}$, in a trans orientation (and the two acac- $O, O$ ligands are in a single plane). Conversely, cis-R-Ir-L is understood to be $c i s-(\text { acac- } O, O)_{2} \operatorname{Ir}{ }^{\mathrm{III}}(\mathrm{L})(\mathrm{R})$ where the non-spectator ligands, $\mathrm{R}$ and $\mathrm{L}$, are in a cis orientation (and the two acac- $O, O$ ligands are not in a single plane). ${ }^{15,16}$ The related mononuclear species, (acac- $O, O)_{2} \operatorname{Ir}(\mathrm{R})(\mathrm{L})$ (where $\mathrm{R}=$ acac, $\mathrm{CH}_{3}, \mathrm{CH}_{2} \mathrm{CH}_{3}$, $\mathrm{Ph}, \mathrm{CH}_{2} \mathrm{CH}_{2} \mathrm{Ph}$ ), also catalyzes rapid benzene-solvent $\mathrm{H} / \mathrm{D}$ exchange. Previously reported experimental and theoretical studies revealed several important conclusions: 1) the dinuclear and mononuclear complexes follow the same mechanistic steps; 2) initiation involves either dissociation of the dinuclear complex or ligand loss from the mononuclear species to generate a reactive 5-coordinate intermediate; 3 ) $\mathrm{C}-\mathrm{H}$ activation involves the 5-coordinate species, requiring trans to cis isomerization of the acac ligand; and 4) the $\mathrm{C}-\mathrm{H}$ activation step is not the rate determining step.

Given the importance and potential broad utility of hydroarylation reactions at reducing halogenated waste and direct access to straight chain alkylbenzenes, ${ }^{17}$ we have begun a systematic study to understand the reactivity and selectivity of the bis$($ acac- $O, O)$ Ir motif in order to design more active catalysts. ${ }^{18}$ We have recently reported a bis-tropolonato $\mathrm{Ir}^{\mathrm{III}}$ analogue which shows a higher rate of $\mathrm{C}-\mathrm{H}$ activation and comparable rates of hydroarylation. ${ }^{19}$ Herein, we present a detailed experimental study of hydroarylation catalyzed by O-donor I $^{\mathrm{III}}$ complexes to expand our understanding of this system and answer the following questions:

(1) Is the observed anti-Markovnikov regioselectivity due to thermodynamic or kinetic control?

(2) Is the active catalyst a dinuclear or mononuclear species?

(3) What are the reaction orders of the substrates?

(4) Why are no $\beta$-hydride elimination products observed?

(5) What is the rate-determining step and complete mechanism for hydroarylation?

\section{Results and discussion}

The (acac- $O, O)_{2}$ Ir motif (Fig. 1) has been well established as both a $\mathrm{C}-\mathrm{H}$ activation and hydroarylation catalyst. ${ }^{11,13,14,15,16}$ For $\mathrm{C}-\mathrm{H}$ activation, the $\mathrm{Ir}^{\mathrm{III}}$ system has been shown to activate 


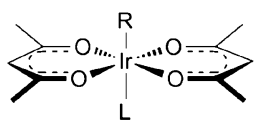

R-Ir-L

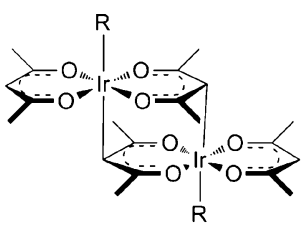

$[R-I r]_{2}$

$R=$ acac, alkyl, aryl
Fig. 1 Acetylacetonato based $\operatorname{Ir}($ III) O-donor complexes studied.

the $\mathrm{C}-\mathrm{H}$ bonds of a wide variety of $\mathrm{sp}^{2}$ and $\mathrm{sp}^{3}$ hydrocarbons both stoichiometrically and catalytically. The motif can tolerate a wide array of substrates and yields predominantly linear alkylarenes as a hydroarylation catalyst. Both mononuclear and dinuclear (acac- $O, O)_{2} \operatorname{Ir}^{\mathrm{III}}$ complexes have been shown to generate a mononuclear cis-(acac-O,O $)_{2} \mathrm{Ir}^{\mathrm{III}}$ species in situ. The most active hydroarylation catalyst previously reported was $\mathbf{P h}$ $\mathbf{I r}-\mathbf{H}_{2} \mathbf{O}$, with a turnover frequency (TOF) of $1.3 \times 10^{-2} \mathrm{~s}^{-1} .^{20}$ Reactions of $\mathbf{P h}-\mathbf{I r}-\mathbf{H}_{2} \mathbf{O}$ in benzene with propylene and styrene led to a ratio of linear:branched products of $61: 39$ (benzene + propylene) and 98:2 (benzene + styrene). Due to the unique selectivity towards linear products, lack of rearrangements, and the lack of $\beta$-hydride elimination products, we were led to examine the mechanism for the hydroarylation reaction in greater detail.

We have previously proposed a mechanism for the hydroarylation reaction involving benzene and an olefin using the (acac$O, O)_{2} \mathrm{Ir}^{\mathrm{III}}$ motif as the catalyst (Scheme 2). ${ }^{16 \mathrm{e}}$ The mechanism entails the dinuclear complex, $[\mathbf{L}-\mathbf{I r}]_{2}$ or the mononuclear complex, R-Ir-L, disassociating into a coordinatively unsaturated species to undergo a trans to cis isomerization followed by benzene $\mathrm{C}-\mathrm{H}$ activation to generate a $c i s$-iridium phenyl intermediate. The olefin then rapidly coordinates to the open coordination site to form cis-Ph-Ir-Ol (Ol = olefin). Alkene insertion into the iridium phenyl bond followed by coordination of benzene yields cis- $\mathbf{P h C H} \mathbf{C H}_{2} \mathbf{C H}_{2}-\mathbf{I r}-\eta^{2}\left(\mathbf{C}_{6} \mathbf{H}_{6}\right)$. C-H bond activation by an oxidative hydrogen migration (OHM) mechanism releases the product and regenerates the iridium phenyl intermediate. ${ }^{11,13,15}$

\section{Catalyst stability}

Initially, we examined if the reaction system was stable over reaction times $>1 \mathrm{~h}$, as previously reported reactions were carried out for $<1$ h. ${ }^{14,16}$ Fig. 2 shows a plot of turnover

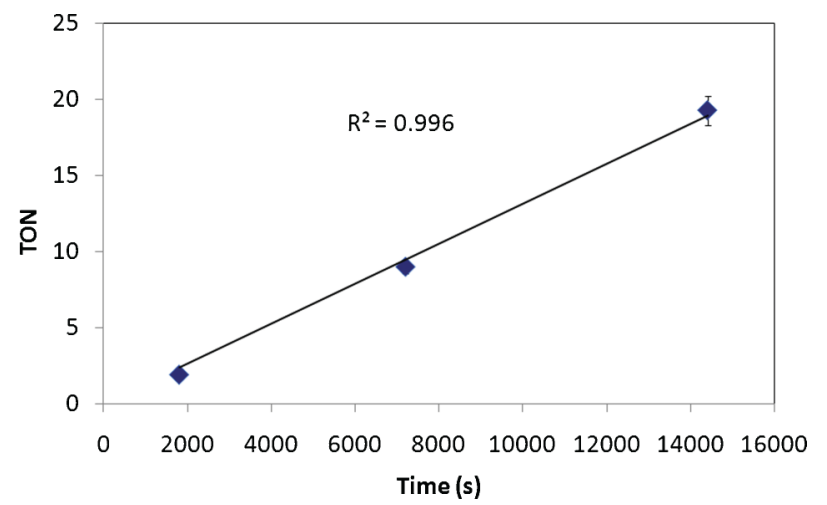

Fig. 2 Time-dependent hydroarylation of propylene using $\mathbf{P h - I r - P y}$ as the catalyst. number (TON) versus time for the hydroarylation reaction between propylene and benzene using Ph-Ir-Py. ${ }^{20}$ The linear relationship between TON and time shows that the catalyst is active and thermally stable at $180{ }^{\circ} \mathrm{C}$ over $4 \mathrm{~h}$. This showcases the impressive thermal stability of the O-donor acac ligands.

\section{Mononuclear or dinuclear catalyst}

In the initial report of hydroarylation by the (acac- $O, O)_{2} \operatorname{Ir}($ III) complexes, we utilized the dinuclear complex, $[\mathbf{A c a c}-\boldsymbol{C}-\mathbf{I r}]_{2} \cdot{ }^{14,16}$ Subsequently, we found that the mononuclear complexes (PhIr-L, Acac- $\boldsymbol{C}$ - $\mathbf{I r}-\mathbf{L}$ where $\mathrm{L}=\mathrm{H}_{2} \mathrm{O}, \mathrm{Py}$, etc.) are also active hydroarylation catalysts. While this suggests that the active catalyst is a mononuclear (acac- $O, O)_{2} \operatorname{Ir}(\mathrm{R})(\mathrm{L})$ complex, it could be speculated that the active catalyst could be a dinuclear Ir species or operating via a bimolecular pathway.

We have previously reported a facile conversion of these dinuclear complexes to stable mononuclear complexes when treated with coordinating ligands $\mathrm{L}$ (where $\mathrm{L}=$ pyridine), ${ }^{16 \mathrm{e}}$ which is inconsistent with dinuclear complexes as the stable, active catalysts. Furthermore, study of the labile $\left[\mathbf{C H}_{3}-\mathbf{I r}\right]_{2}$ complex by ${ }^{1} \mathrm{H}$ and ${ }^{13} \mathrm{C}$ NMR revealed that dissociation to stable 5-coordinate square pyramidal complexes (or 6-coordinate solvento complexes) occurs with an activation parameter $\left(\Delta G_{298 \mathrm{~K}}^{\dagger}\right)$ of $14.1 \pm 0.5 \mathrm{kcal} \mathrm{mol}^{-1}$, which is lower than the $\Delta G^{\ddagger}$ barrier for hydroarylation. ${ }^{16 \mathrm{e}}$

Examination of the predicted rate laws for a mononuclear catalytic species versus a dinuclear catalytic species generated in situ shows concentration dependence on L (Scheme 3). If we presume that the active catalyst is a dinuclear complex (M-M) and that it is in equilibrium with the catalyst precursor, M$\mathrm{L}$, then the rate law will be proportional to $[\mathrm{M}-\mathrm{L}]^{2} /[\mathrm{L}]^{2}$ under steady state conditions. This is reasonable if the equilibrium constant for the formation of M-M or the amount of $\mathrm{L}$ formed from dissociation of $\mathrm{M}-\mathrm{L}$ are small. Consistent with these assumptions, VT-NMR analysis of a $\mathrm{C}_{6} \mathrm{D}_{6}$ solution of $\mathbf{P h}-\mathbf{I r}$ Py at $100{ }^{\circ} \mathrm{C}$ showed no detectable free pyridine or dinuclear complexes. These results are also consistent with previous theoretical calculations that indicate that both reactions are endoergic with a $\Delta G>5 \mathrm{kcal} \mathrm{mol}^{-1} \cdot$. $^{11,13,15}$

If the catalyst is the dinuclear complex M-M, plotting the TOF vs. $\left[1 / \mathrm{L}^{2}\right]$ should yield a straight line. On the other hand, if the active catalyst is the mononuclear species "M" generated by the loss of L from added M-L, then plotting TOF $v s$. [1/L] should yield a straight line at constant [M-L]. Analysis of reactions charged with varying amounts of pyridine (2-10 eq.) under standard pseudo first order conditions ${ }^{21}$ at $180^{\circ} \mathrm{C}$ for $30 \mathrm{~min}$ in a temperature controlled oil bath, yields a linear correlation $\left(\mathrm{R}^{2}=\right.$ 0.997 ) when $1 /$ (equivalents of pyridine) is plotted against TOF as shown in Fig. 3. The linear correlation for Ph-Ir-Py strongly indicates a mononuclear catalyst as the active species. The system is also inhibited by pyridine suggesting a coordination catalysis mechanism.

\section{Reaction order of substrates}

Next, we wanted to examine the order of the various reactants (benzene, catalyst, and olefin) present during reaction. The reaction order on benzene was determined using Ph-Ir-Py as the catalyst in cyclohexane. Control reactions have shown that 


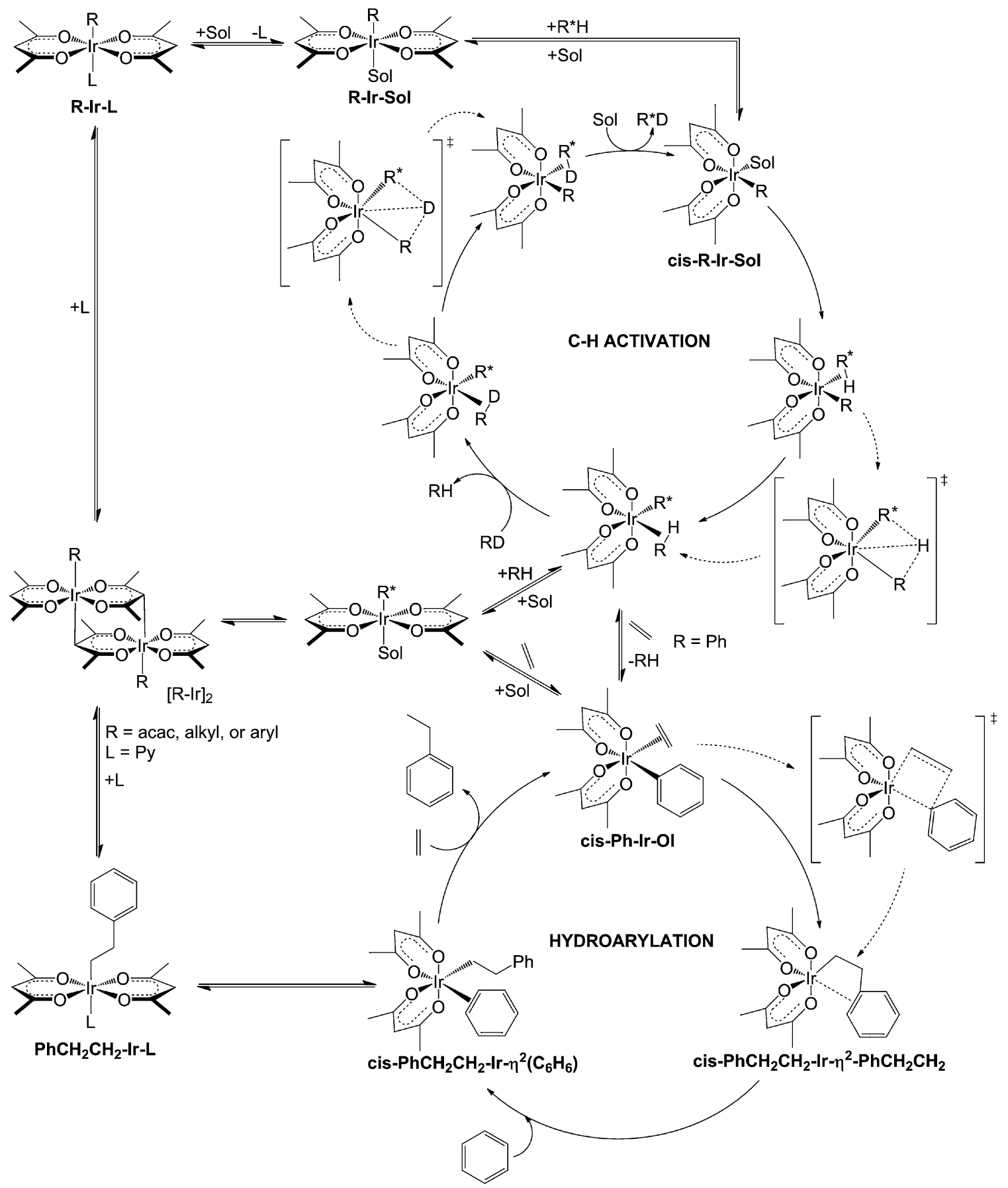

Scheme 2 Catalytic cycle for the hydroarylation reaction using [L-Ir $]_{2}$ or R-Ir-L.

cyclohexane does not react under hydroarylation conditions and therefore can be used as an inert solvent for examining the order of benzene. A $10 \mathrm{~mL}$ glass Schlenk bomb flask fitted with a resealable Teflon valve and a magnetic stir bar was charged with dry, distilled benzene $(0.1$ to $1 \mathrm{~mL})$, styrene $(0.6 \mathrm{~mL})$ and $0.1 \mathrm{~mol} \%$ of catalyst from a stock solution. The solution was heated to $180{ }^{\circ} \mathrm{C}$ for $30 \mathrm{~min}$ in a well stirred, temperature controlled oil bath. Analysis of the reaction mixture by GC-MS and referenced to the internal standard, yields the data shown in Fig. 4. A linear relationship exists between benzene concentra- tion and TOF, which is expected for first-order dependence on benzene.

The hydroarylation of olefins to generate mono-alkylarenes is typically carried out at $\sim 200^{\circ} \mathrm{C}$ with a 5-10 $\mathrm{mM}$ catalyst loading in $1 \mathrm{~mL}$ of neat arene (which acts as both reactant and solvent) and $10-20 \mathrm{~mol} \%$ olefin. Studies of olefin concentration (with styrene as the olefin) under these conditions show a complicated dependence (Fig. 5) on concentration. The initial increase in the TOF is consistent with a first order dependence on olefin; however, higher concentrations of olefin lead to a drastic drop 


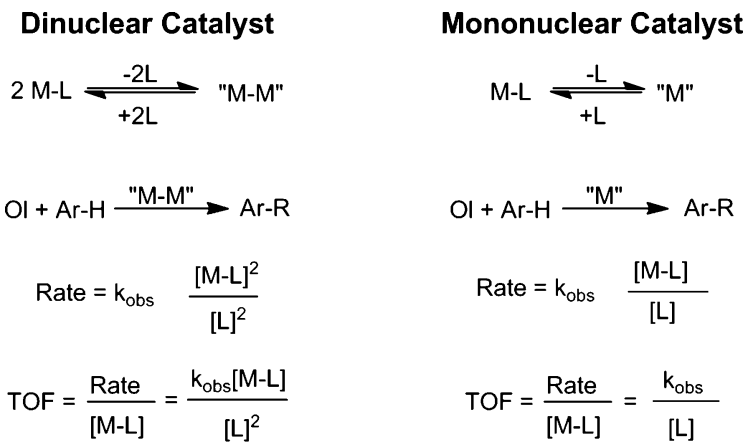

Scheme 3 TOF dependence on $[\mathrm{L}]$ for dinuclear and mononuclear complexes.

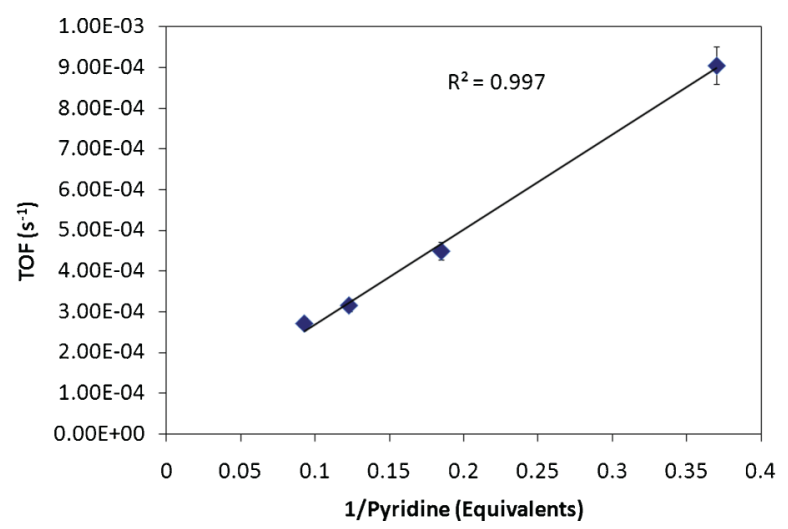

Fig. 3 TOF vs. 1/equivalents of pyridine catalyzed by Ph-Ir-Py.

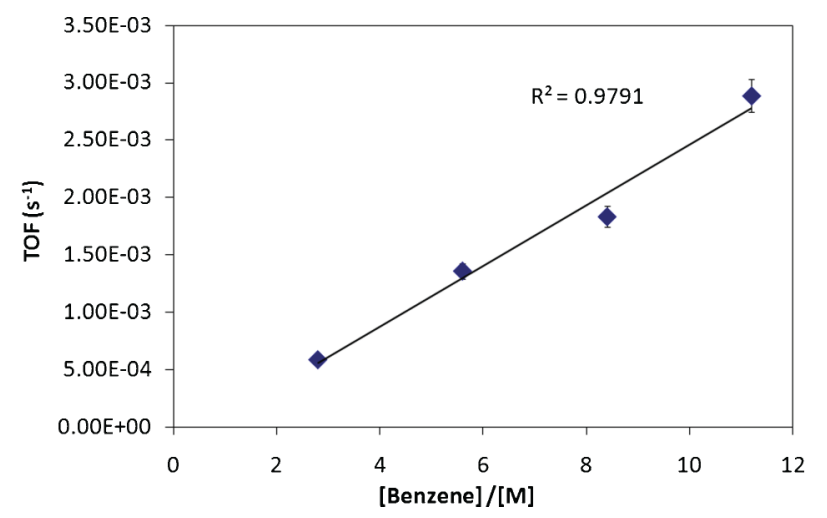

Fig. 4 Kinetic dependence of hydroarylation on benzene concentration using Ph-Ir-Py.

in catalytic rate. We previously had observed inhibition by high concentrations of olefin. ${ }^{15,16}$ Likely, high olefin concentrations leads to a ground-state stabilization effect by binding to the Ir center and thus effectively blocking arene binding that is required for catalysis.

As the concentration of free $\mathrm{L}$ during catalysis could not be easily determined, we carried out reactions in the presence of excess $\mathrm{L}\left(\mathrm{L}_{0}>1\right.$ eq. of added catalyst) as this allows the simplification that $\mathrm{L}=\mathrm{L}_{0}$ if we assume that the pre-equilibrium term, $K_{1}$, is small. Based on the proposed mechanism (Scheme 2) (1,13,15,16 $^{1}$ and as can be seen from the simplified rate law in Scheme 4, a first order dependence on the concentrations of catalyst, olefin and benzene is predicted along with an inverse dependence on $\mathrm{L}$. We have previously shown that both $\mathrm{C}-\mathrm{H}$ activation

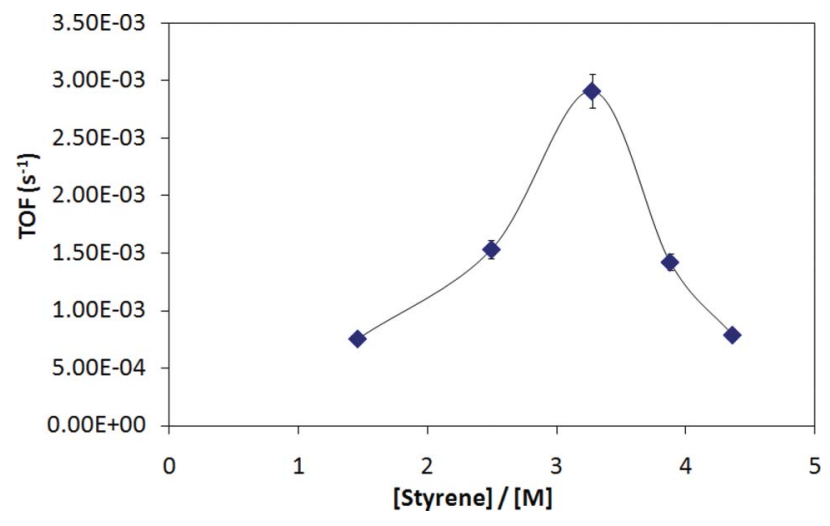

Fig. 5 Kinetic dependence of hydroarylation on olefin concentration.

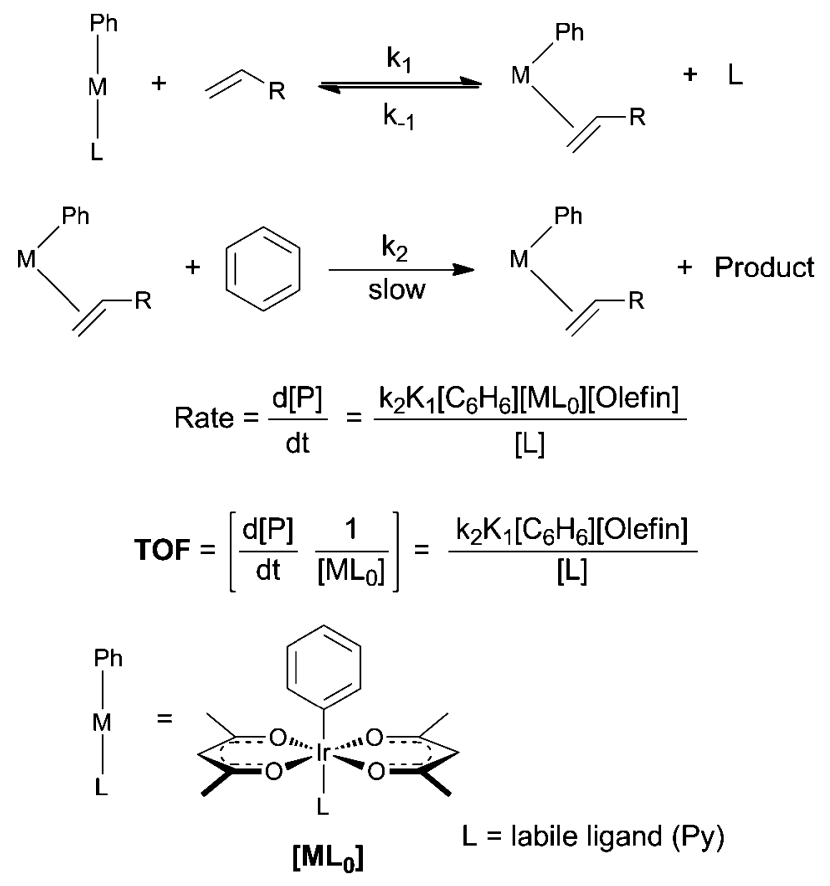

Scheme 4 Proposed rate law for Ph-Ir-Py.

and hydroarylation show first order dependence on the catalyst $(\text { acac- } O, O)_{2} \operatorname{Ir}(\mathrm{R})(\mathrm{L}) .{ }^{16}$ As can be seen from the data there is an inverse dependence on $\mathrm{L}$ and a first order dependence on benzene and olefin at low pressures.

\section{Thermodynamic vs. kinetic control}

A key feature of the (acac- $O, O)_{2} \operatorname{Ir}^{\mathrm{III}}$ catalysts is the preference for anti-Markovnikov regioselectivity in olefin hydroarylation to give straight-chain (linear) alkylbenzenes. However, based on DFT calculations, ${ }^{11,13,15}$ the $40: 60$ ratio of iso- to $n$-propyl benzene can be expected based on the thermodyanmic heats of formation of the products (see Supporting Information $\dagger$ ). ${ }^{22}$ Therefore, we wanted to examine whether the reaction is under thermodynamic or kinetic control.

For the insertion to be under thermodynamic control, it is required that a facile pathway be available for the intramolecular interconversion of the $n$-propyl and isopropyl benzene isomers under the conditions required for hydroarylation reaction. Importantly, such alkylarene isomerizations must not be 
Table 1 Comparison of the thermodynamic and experimental ratio for hydroarylation with various olefins where the expected thermodynamic ratio is based on relative free energies via DFT using B3LYP/LACV3P++**//LACVP** (see Supporting Information $\dagger$ )

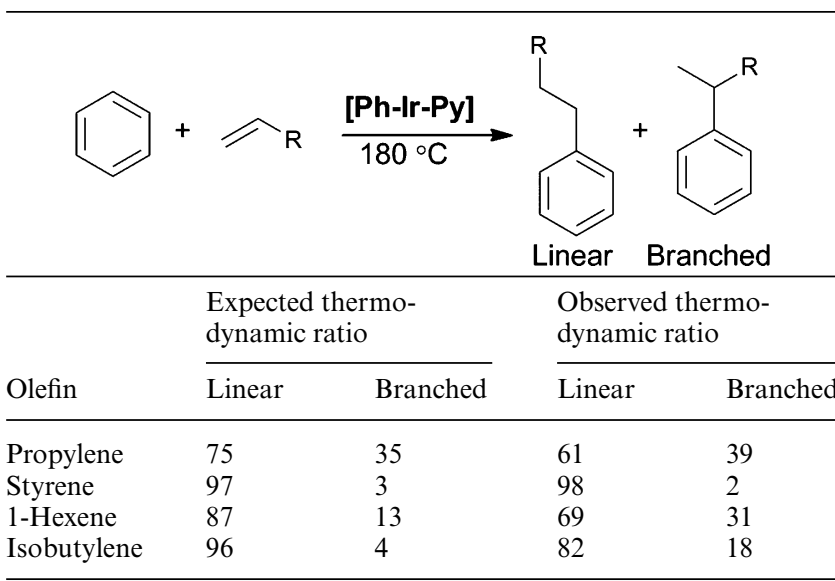

accompanied by intermolecular trans-alkylation (reactions that transfer alkyl groups between different arenes), because in that case, the predicted thermodynamic products would be expected to be poly-alkylarenes (e.g. di- $n$-propylbenzene or di-iso-propylbenzene), which are not observed by GC-MS or NMR analysis. To test the possibility that a selective intramolecular alkylarene isomerization catalyst is generated, isopropyl benzene was monitored under the hydroarylation conditions (i.e., in the presence of benzene and the catalyst, Ph-Ir-Py) to detetermine if rearrangement occurs to yield the thermodynamically more stable $n$-propyl benzene isomer (eqn (1)). GCMS analysis of the resulting reaction mixture showed that the isopropyl benzene remains unchanged and no $n$-propyl benzene was formed (Table 1). To further mimic reaction conditions, the reaction was repeated in the presence of ethylene to rule out the possibility that the potential active catalyst is generated only in the presence of olefins. Under these conditions, while ethyl benzene is observed (indicating that an active hydroarylation catalyst is present) no rearrangement of isopropyl benzene occurs and $n$-propyl benzene is not observed. These experiments rule out the possibility that the anti-Markovnikov selectivity stems from thermodynamic control during the hydroarylation reaction and suggest that the similarity between the thermodynamic and the observed product distribution with propylene is merely coincidental. This leads to the conclusion that the reaction operates under kinetic control.

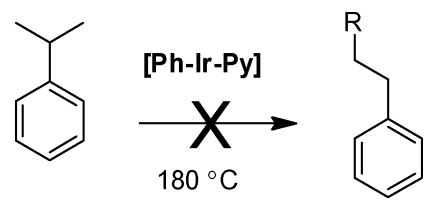

It is interesting to note that the same regioisomers are observed in the well documented Heck reaction. ${ }^{23}$ The common step of both the Heck and hydroarylation reactions is the insertion of the olefin into a $\mathrm{M}-\mathrm{Ph}$ bond. Based on our theoretical results, electronic and steric factors both contribute to controlling the reaction selectivity. ${ }^{11}$

The olefin insertion step with the $\mathrm{Ph}-\mathrm{Ir}$ olefin intermediate, cis-Ph-Ir-OI, is proposed to control the anti-Markovnikov re-
Table 2 Stoichiometric products after treatment of $\mathbf{P h}-\mathbf{I r}-\mathbf{P y}$ with $\mathrm{R}-$ $\mathrm{CH}=\mathrm{CH}_{2}$, where $\mathrm{R}=\mathrm{C}_{6} \mathrm{H}_{5}, \mathrm{CH}_{3}$, or $\mathrm{C}_{4} \mathrm{H}_{9}$

\begin{tabular}{lllll}
\hline $\mathrm{R}$ group & Linear/L & Branched (B) & L:B Ratio & Benzene (\%) \\
\hline $\mathrm{CH}_{3}$ & 40 & 27 & $61: 39$ & 33 \\
$\mathrm{Ph}_{\mathrm{C}_{4} \mathrm{H}_{9}}$ & 59 & 1 & $98: 2$ & 60 \\
\hline
\end{tabular}

gioselectivity. To investigate this step, we examined the stoichiometric reaction of $\mathbf{P h}$-Ir-Py with various olefins and determined a hydrogen donor is required for the generation of alkylarenes. In the proposed catalytic reaction mechanism, this is provided by the arene co-reactant in the $\mathrm{C}-\mathrm{H}$ activation step, or from the olefin via vinylic $\mathrm{C}-\mathrm{H}$ bond activation. However, since the $\mathrm{C}-\mathrm{H}$ activation step is much faster than insertion, mesitylene was used as a solvent (rather than benzene) to allow for only stoichiometric reactivity. Control experiments showed that olefin hydroarylation reaction between benzene and propylene catalyzed by $\mathbf{P h}-\mathbf{I r}-\mathbf{P y}$ is uneffected by added mesitylene. NMR spectra of these reactions show that the organometallic complex after the reaction is either Mes-Ir-L or vinyl-Ir-L, the latter being the major product. ${ }^{16 \mathrm{~d}, 24}$

The stoichiometric reaction was studied using Ph-Ir-Py (15 mmol) with olefins such as propylene, ethylene, styrene and 1hexene in liquid mesitylene at $180^{\circ} \mathrm{C}$ for $20 \mathrm{~min}$. The gas and liquid phases were analyzed by GC-MS to identify and quantify the reaction products. The solvent was then removed and the non-volatile reaction products were dissolved in $\mathrm{CDCl}_{3}$ and analyzed by NMR (Table 2). Addition of styrene $(\mathrm{R}=\mathrm{Ph})$ to $\mathbf{P h}$ Ir-Py in mesitylene yields $40 \%$ of the hydroarylation products, dihydrostilbene and 2,2-diphenylethane in a $98: 2$ ratio, along with $60 \%$ benzene (the total yield of linear + branched + benzene is $100 \%$ with respect to $\mathbf{P h - I r - P y ) . ~ S i m i l a r l y , ~ a d d i t i o n ~ o f ~ 1 - h e x e n e ~}$ $\left(\mathrm{R}=\mathrm{C}_{4} \mathrm{H}_{9}\right)$ leads to the formation of 1-phenyl hexane and 2phenyl hexane in a $69: 31$ ratio, along with free benzene. Identical regioselectivity was observed when cis-Ph-Ir-Py was used in lieu of Ph-Ir-Py.

In addition to hydroarylation products, a substantial amount of benzene is generated along with derivatives of the corresponding vinyl-Ir-L complex. Benzene should be the product of the microscopic reverse $\mathrm{C}-\mathrm{H}$ transfer step:

$$
\begin{gathered}
\text { Ph-Ir-Py }+\mathrm{CH}_{2}=\mathrm{CHR} \rightarrow \text { cis-Ph-Ir- }\left(\mathbf{C H}_{2}=\mathbf{C H R}\right)+\mathrm{Py} \\
\rightarrow \text { cis- }\left(\mathbf{C H}_{2}=\mathbf{C R}\right)-\mathrm{IR}-\mathbf{C}_{6} \mathbf{H}_{6}+\mathrm{Py} \rightarrow(\mathbf{C H} 2=\mathbf{C R})-\mathrm{Ir}-\mathrm{Py} \\
+\mathrm{C}_{6} \mathrm{H}_{6}
\end{gathered}
$$

During the catalytic cycle, this transformation is expected to be reversible and would yield the olefin intermediate, cis-Ph-IrOl. However, in the stoichiometric reaction, the concentration of benzene is sufficiently low to trap the vinyl intermediate.

From these results, there are two important observations. First, the stoichiometric reactions of $\mathbf{P h}$-Ir-Py with olefins results in the same ratios of branched to linear alkylarene products as those observed in olefin hydroarylation catalysis. This suggests 


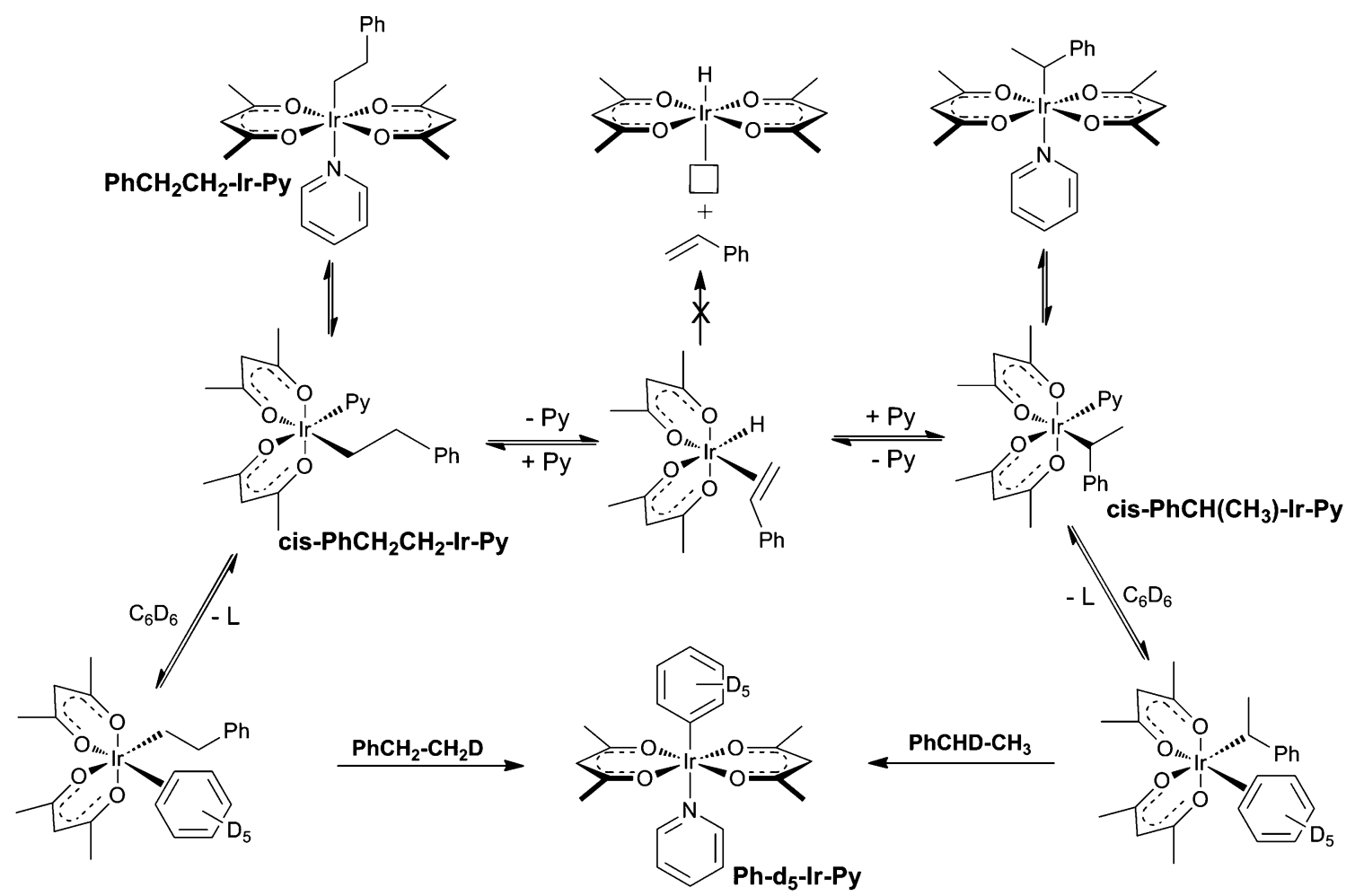

Scheme 5 Reversible versus irreversible $\beta$-hydride elimination.

that our catalyst structure is maintained in the catalytic cycle, and no induction period is required for catalysis. Second, the presence of both the hydroarylated product and benzene in the non-complete stoichiometric reactions shows that both $\mathrm{C}-\mathrm{H}$ activation and insertion occurs in this system. However, the observed relative rates of (linear + branched) vs. benzene does not allow us to determine relative rates of insertion vs. $\mathrm{C}-\mathrm{H}$ activation.

\section{$\beta$-Hydride elimination}

It is well known that metal-alkyl complexes possessing $\beta-\mathrm{C}-\mathrm{H}$ bonds are susceptible to facile $\beta$-hydride elimination reactions. ${ }^{25}$ During hydroarylation reactions using the (acac- $O, O)_{2}$ Ir motif no olefin products are observed during post reaction analysis. ${ }^{16}$ Additionally, analysis of the liquid and gas phases of the stoichiometric $\mathrm{C}-\mathrm{H}$ activation reactions between both $\mathbf{P h C} \mathbf{C H}_{2} \mathbf{C H}_{2}-$ Ir-Py and $\mathbf{C H}_{3} \mathbf{C H}_{2}$-Ir-Py with benzene, by NMR and GC-MS showed that no olefinic products (such as styrene or ethylene) or Ir bound olefins were formed. ${ }^{14,16}$ Olefin products would be expected from irreversible $\beta$-hydride elimination reactions from the coordinatively unsaturated intermediates cis- $\mathbf{P h C H} \mathbf{C H}_{2} \mathbf{C H}_{2}-\mathbf{I r}$ and cis- $\mathbf{C H}_{3} \mathbf{C H}_{2}$-Ir. The observation that only $\mathrm{PhCH}_{2} \mathrm{CH}_{2} \mathrm{D}$ is quantitatively formed from the stoichiometric $\mathrm{CH}$ activation of $\mathrm{C}_{6} \mathrm{D}_{6}$ with $\mathbf{P h C} \mathbf{C H}_{2} \mathbf{C H}_{2}$-Ir-Py is only negative evidence towards $\beta$-hydride elimination reactions occurring. Complete lack of olefinic products could suggest that $\beta$-hydride elimination reactions either do not occur or are reversible and unproductive (Scheme 5). Given these plausible possibilities, the selective formation of $\mathrm{PhCH}_{2} \mathrm{CH}_{2} \mathrm{D}$ from the $\mathrm{C}-\mathrm{H}$ activation of $\mathrm{C}_{6} \mathrm{D}_{6}$ with $\mathrm{PhCH}_{2} \mathrm{CH}_{2}-\mathrm{Ir}-\mathrm{Py}$ does not rule out the possibility that reversible, unproductive $\beta$-hydride elimination reactions occur. Previous DFT calculations ${ }^{15}$ have suggested that reversible $\beta$ hydride elimination is favorable, but that such reactions are reversible and unproductive. The calculated barrier for dissociative loss of olefin from the saturated, 6-coordinate hydride intermediates is higher than the barrier for the $\mathrm{C}-\mathrm{H}$ activation step (Scheme 4).

Metal alkyls that possess $\beta-\mathrm{C}-\mathrm{H}$ bonds, but do not react to generate olefins, could be useful in a variety of catalytic reactions (polymerization, hydroarylation, etc.). To further the understanding about the selectivity towards alkylarenes, the $\alpha$ ${ }^{13} \mathrm{C}$-labelled complex, $\mathbf{C H}_{3}{ }^{13} \mathbf{C H}_{2}$-Ir-Py, was synthesized by a route analagous to $\mathbf{C H}_{3}$-Ir-Py and the $\mathrm{C}-\mathrm{H}$ activation with $\mathrm{C}_{6} \mathrm{D}_{6}$ was examined. ${ }^{16 d}$ The ethyl-Ir complex was chosen because it would not show a steric or electronic bias to possible $[1,2]-$ Ircarbon rearrangements from reversible $\beta$-hydride elimination reactions. $\mathbf{C H}_{3}{ }^{13} \mathbf{C H}_{2}$-Ir-Py was synthesized using ${ }^{13} \mathrm{C}$-labelled $\mathrm{Et}_{2} \mathrm{Hg}$. As shown in Scheme 6, if reversible $\beta$-hydride elimination does occur with $\mathbf{C H}_{3}{ }^{13} \mathbf{C H}_{2}$-Ir-Py, this would lead to migration of the ${ }^{13} \mathrm{C}$-label from the $\alpha$ to the $\beta$-position and formation of the ${ }^{13} \mathbf{C H}_{3} \mathbf{C H}_{2}$-Ir-Py regioisomer. Indeed, carrying out this reaction in $\mathrm{C}_{6} \mathrm{D}_{6}$ led to two regioisomers of ethane: ${ }^{13} \mathrm{CH}_{3} \mathrm{CH}_{2} \mathrm{D}$ and ${ }^{13} \mathrm{CH}_{2} \mathrm{DCH}_{3}$ (formed by $\mathrm{C}-\mathrm{D}$ activation of the $\mathrm{C}_{6} \mathrm{D}_{6}$ solvent and loss of ${ }^{13} \mathrm{C}$-ethane). The progress of the $\mathrm{C}-\mathrm{H}$ activation reaction was monitored by ${ }^{13} \mathrm{C}\left\{{ }^{1} \mathrm{H}\right\}$ (with sufficiently long relaxation delay to afford accurate integration of the ${ }^{13} \mathrm{C}$ resonances) and ${ }^{1} \mathrm{H}$ NMR as shown in Fig. 6. The study of the reaction progress shows evidence for the migration of the ${ }^{13} \mathrm{C}$ label of $\mathbf{C H}_{3}{ }^{13} \mathbf{C H}_{2}-$ Ir-Py $(\sim-9$ ppm) from the $\alpha$ to the $\beta$-position, resulting in a formation of the $\beta-{ }^{13} \mathrm{C}$ regio-isotopomer, ${ }^{13} \mathbf{C H}_{3} \mathbf{C H}_{2}$-Ir-Py ( 18 ppm). 


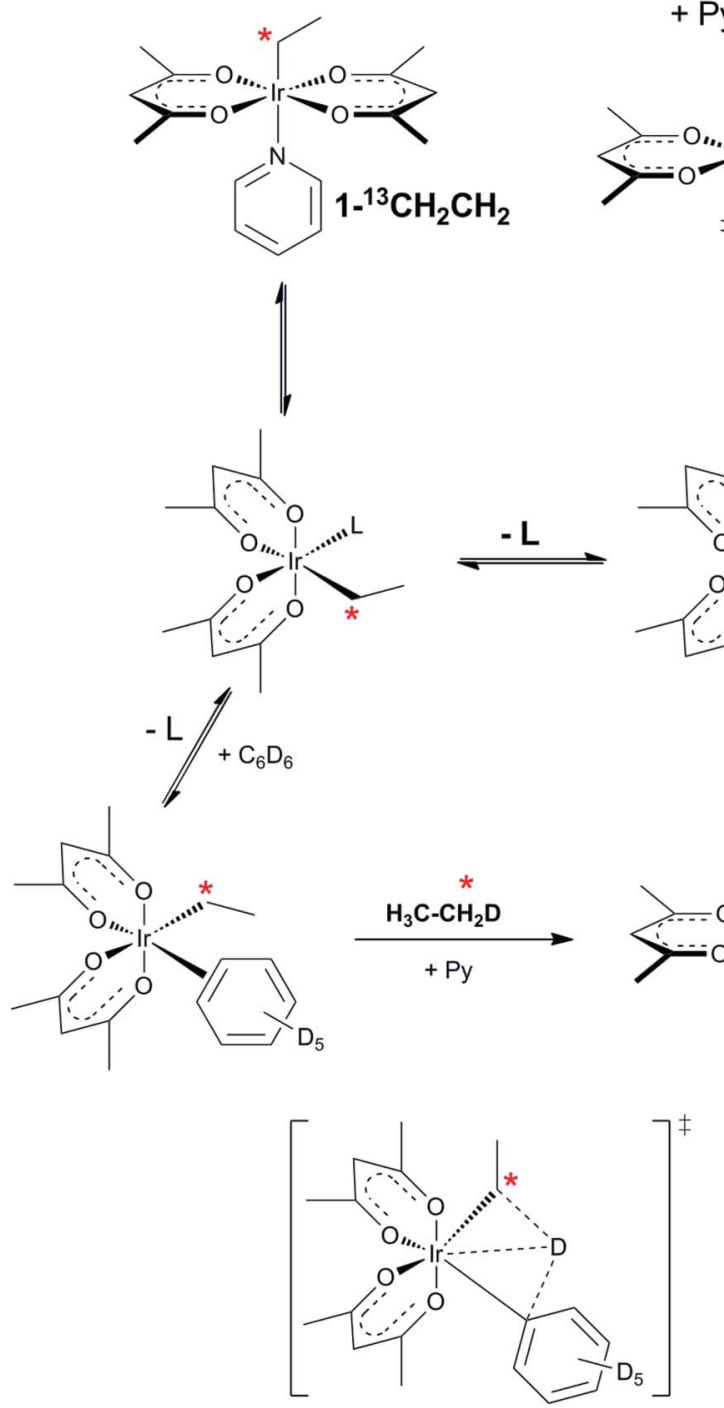<smiles>CC1CC1O[Te]([O-])(OC1CC1)OC1(C)CC1(C)C</smiles>
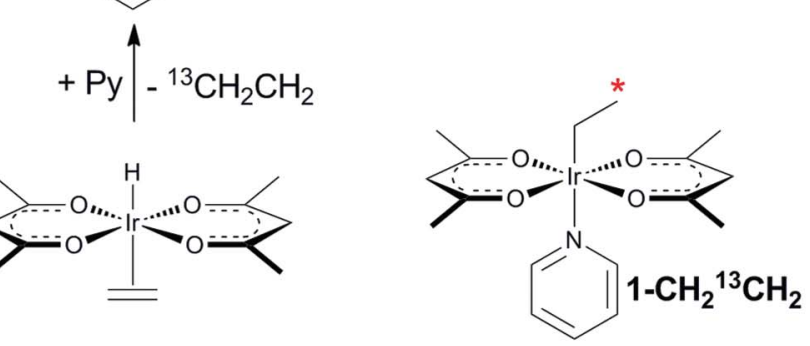

$\mathrm{L}=$ pyridine<smiles>C=CI</smiles>
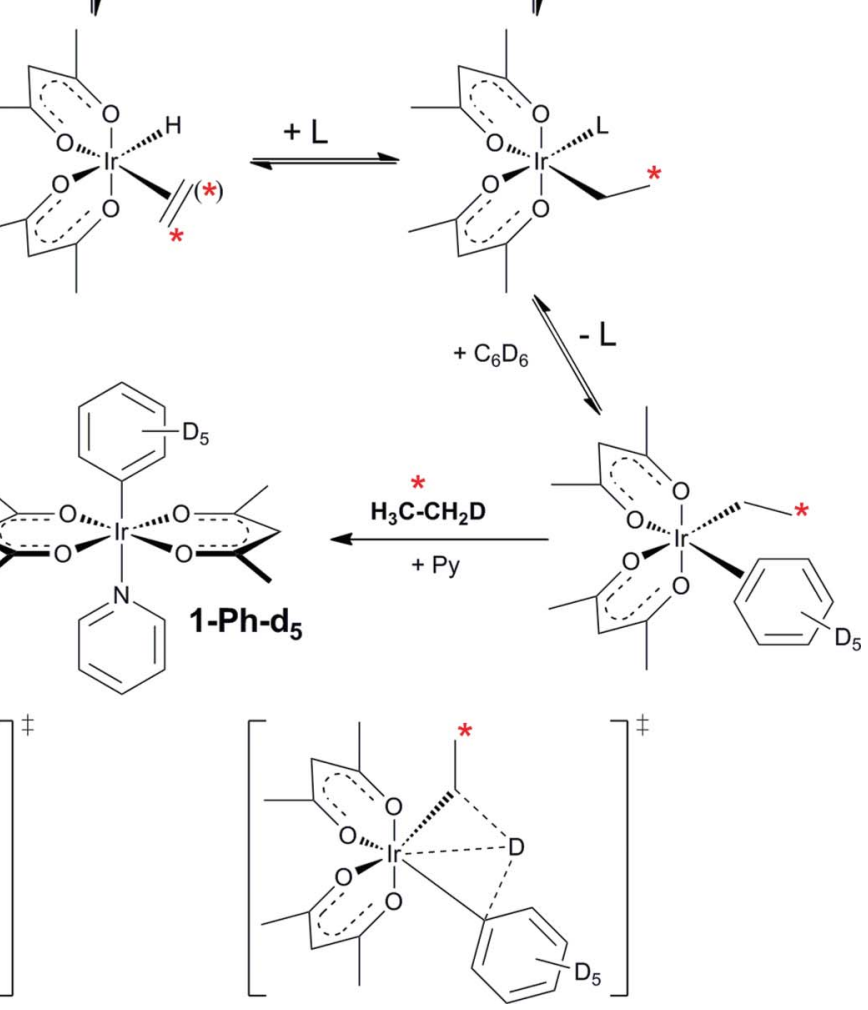

Scheme 6 Possible products expected from heating $\mathrm{CH}_{3}{ }^{13} \mathrm{CH}_{2}$-Ir-Py in $\mathrm{C}_{6} \mathrm{D}_{6}$ to generate ethane by $\mathrm{C}-\mathrm{H}$ activation showcasing reversible but unproductive $\beta$-hydride elimination.

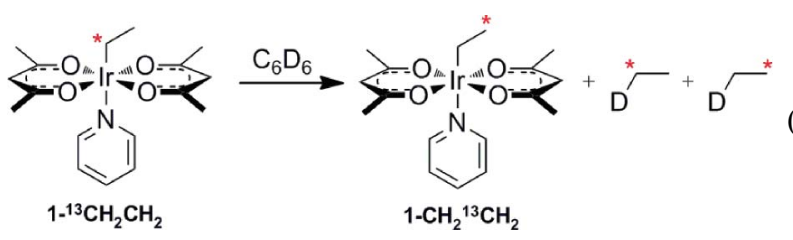

Fig. 6 also shows that a steady state concentration of the $\beta$ isomer, ${ }^{13} \mathbf{C H}_{3} \mathbf{C H}_{2}-\mathbf{I r}-\mathbf{P y}(\sim 18 \mathrm{ppm})$, is generated but the concentration is substantially lower than the $\mathbf{C H}_{3}{ }^{13} \mathbf{C H}_{2}$-Ir-Py present $(-9 \mathrm{ppm})$. This indicates that reversible $\beta$-hydride elimination does occur and accounts for the $\alpha$ to $\beta$-migration of the ${ }^{13} \mathrm{C}$ - label of $\mathbf{C H}_{3}{ }^{13} \mathbf{C H}_{2}$-Ir-Py. Importantly, the lack of formation of equimolar amounts of $\mathbf{C H}_{3}{ }^{13} \mathbf{C H}_{2}-$ Ir-Py and ${ }^{13} \mathbf{C H}_{3} \mathbf{C H}_{2}-\mathrm{Ir}-\mathrm{Py}$ as ethane is lost with concomitant $\mathrm{C}-\mathrm{H}$ activation of $\mathrm{C}_{6} \mathrm{D}_{6}$, strongly indicates that the $\alpha$ to $\beta$-migration of the ${ }^{13} \mathrm{C}$-label is slower than both the $C-H$ activation of benzene and the formation of ethane with $\boldsymbol{P h}-\boldsymbol{d}_{5}-\boldsymbol{I r}-\boldsymbol{P} \boldsymbol{y}$. This result is confirmed by analysis of the dissolved ethane produced from arene $\mathrm{C}-\mathrm{H}$ activation. Thus, both regioisomers of mono- ${ }^{2} \mathrm{H},{ }^{13} \mathrm{C}$-ethane ( $~ 8 \mathrm{ppm}$ composed of a singlet from ${ }^{13} \mathrm{CH}_{3} \mathrm{CH}_{2} \mathrm{D}$ and a $1: 1: 1$ triplet from ${ }^{2} \mathrm{H}-{ }^{13} \mathrm{C}$ coupling in ${ }^{13} \mathrm{CH}_{2} \mathrm{DCH}_{3}$ ) are generated from the $\mathrm{C}-\mathrm{H}$ activation of $\mathrm{C}_{6} \mathrm{D}_{6}$ as shown in eqn (2). Simulation of this pattern readily shows that the predominant ethane product is ${ }^{13} \mathrm{CH}_{2} \mathrm{DCH}_{3}$ 


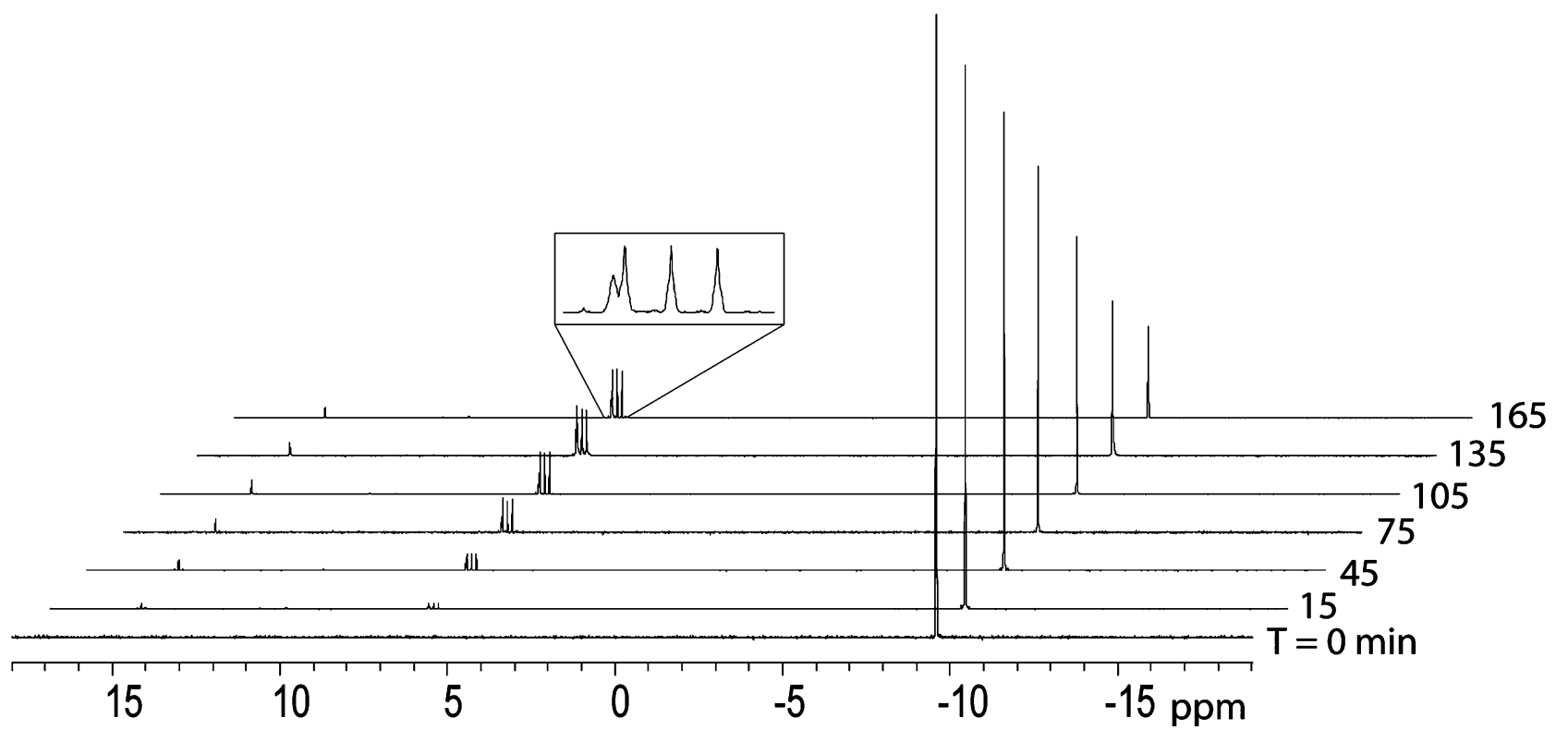

Fig. 6 Time dependent ${ }^{13} \mathrm{C}$ NMR spectra for the reaction of $\mathrm{CH}_{3}{ }^{13} \mathrm{CH}_{2}-\mathrm{Ir}-\mathrm{Py}(-9 \mathrm{ppm})$ with $\mathrm{C}_{6} \mathrm{D}_{6}$ to form ${ }^{13} \mathrm{CH}_{3} \mathrm{CH}_{2}-\mathrm{Ir}-\mathrm{Py}(18$ ppm) and two regioisomers of ethane ( $8 \mathrm{ppm})$.

with $\sim 16 \mathrm{~mol}^{\%}$ of ${ }^{13} \mathrm{CH}_{3} \mathrm{CH}_{2} \mathrm{D}$ and that this ratio is essentially constant over the course of the reaction. Analyses by ${ }^{1} \mathrm{H}$ NMR also confirms (on the basis of the acac resonances) that $\mathbf{P h}-\mathbf{d}_{\mathbf{5}}$ Ir-Py is the only new (acac- $O, O)_{2}$ Ir product formed after loss of ethane.

Importantly, rate measurements of the migration of the ${ }^{13} \mathrm{C}$ label in $\mathbf{C H}_{3}{ }^{13} \mathbf{C H}_{2}$-Ir-Py and/or the relative ratio of the two regioisomers of ethane could both be expected to provide information on the relative rates of reversible $\beta$-hydride elimination versus benzene $\mathrm{C}-\mathrm{H}$ activation. This was further examined through the data gathered from NMR experiments (Fig. 6). An assumption that the formation of ${ }^{13} \mathbf{C H}_{3} \mathbf{C H}_{2}$-Ir-Py is under steady-state conditions was applied to the kinetic analysis. It is assumed that $\mathrm{C}-\mathrm{H}$ activation operates via a bimolecular pathway based on the concentration of benzene. $\beta$-hydride elimination is observed via ${ }^{13} \mathrm{C}$ migration of the ethane label suggesting a unimolecular reaction pathway. Comparison of the ratio of rate constants for the $\mathrm{C}-\mathrm{H}$ activation to $\beta$-hydride elimination $\left(k_{\mathrm{CH}}: k_{\beta}\right)$ reactions gives a ratio of ${ }^{13} \mathrm{CH}_{2} \mathrm{DCH}_{3}$ to ${ }^{13} \mathrm{CH}_{3} \mathrm{CH}_{2} \mathrm{D}$ of $\sim 0.5$ (Scheme 7).

The comparable rate constants for $\mathrm{C}-\mathrm{H}$ activation and $\beta$ hydride elimination would seem to suggest a common rate determining intermediate for both processes, as was seen for the $\mathrm{C}-\mathrm{H}$ activation and the trans-cis isomerization reactions of (acac- $\mathrm{O}, \mathrm{O})_{2} \mathrm{Ir}$ complexes. ${ }^{16 \mathrm{e}}$ The intermediate is most likely, cisR-Ir-Sol, where $\mathrm{R}=\mathrm{CH}_{3} \mathrm{CH}_{2}$ - in this case. Indeed, previous theoretical calculations have shown that the formation of the cis-Et-Ir-Sol intermediate is rate determining and the rates for $\mathrm{C}-\mathrm{H}$ activation and hydroarylation are equivalent. ${ }^{11,13,15}$

These findings should be contrasted to the related but more electron rich Ir ${ }^{\mathrm{III}}$ complex, $\left[\mathrm{Cp}^{*}\left(\mathrm{PMe}_{3}\right) \operatorname{IrR}(\mathrm{OTf})\right]$, which undergoes irreversible $\beta$-hydride elimination to form very stable olefin metal hydrides that inhibit catalysis. ${ }^{26}$ Another closely related molecule, $\operatorname{TpIr}(\text { olefin })_{2}$, has been shown to transform into $\mathrm{Ir}^{\mathrm{III}}$ vinyl hydride isomers, $\left[\mathrm{Tp} \operatorname{Ir}\left(\mathrm{CH}=\mathrm{CH}_{2}\right) \mathrm{H}\left(\mathrm{C}_{2} \mathrm{H}_{4}\right)\right]$, which

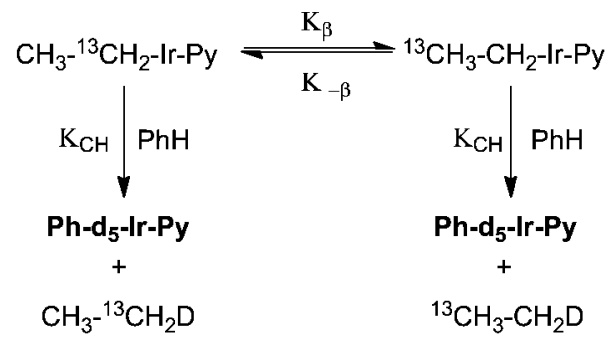

$$
\begin{gathered}
\frac{\delta\left[\mathrm{CH}_{3}{ }^{13} \mathrm{CH}_{2} \mathrm{D}\right]}{\delta\left[\mathrm{CH}_{2} \mathrm{D}^{13} \mathrm{CH}_{3}\right]}=\frac{\left[\mathrm{CH}_{3}^{13} \mathrm{CH}_{2} \mathrm{D}\right]}{\left[\mathrm{CH}_{2} \mathrm{D}^{13} \mathrm{CH}_{3}\right]}=\frac{\mathrm{k}_{\mathrm{CH}}[\mathrm{PhH}]}{\mathrm{k}_{\beta}} \approx \frac{1}{0.16} \\
\frac{\mathrm{k}_{\mathrm{CH}}}{\mathrm{k}_{\beta}}=\frac{\left[\mathrm{CH}_{3}{ }^{13} \mathrm{CH}_{2} \mathrm{D}\right]}{\left[\mathrm{CH}_{2} \mathrm{D}^{13} \mathrm{CH}_{3}\right][\mathrm{PhH}]} \approx 0.5
\end{gathered}
$$

Scheme 7 Kinetic scheme for $\mathrm{C}-\mathrm{H}$ activation and $\alpha$ to $\beta{ }^{13} \mathrm{C}$-migration.

are also the thermodynamically most stable products. ${ }^{27}$ This comparison highlights an important characteristic of the more electronegative O-donor complexes. Unlike the more electron rich compounds, the O-donor acac system avoids a thermodynamic sink of irreversible olefin binding by reducing the electron density on the Ir and allows for reversible olefin binding.

\section{Proposed mechanism}

The proposed mechanism of the hydroarylation reaction catalyzed by the O-donor, (acac- $O, O)_{2} \mathrm{Ir}^{\mathrm{III}}$ complexes is shown in Scheme 2. As previously reported, the trans complexes are the kinetic products that are isolated during synthesis, which upon heating lead to the quantitative formation of the thermodynamically stable $c i s$ isomers when trapped with excess L such as pyridine. ${ }^{16}$ The reaction mechanism is proposed to proceed 
via three key steps: 1) a pre-equilibrium, or isomerization step(s), that generates the "active catalyst", independent of which R-Ir-L complex is used to catalyze the reaction, 2) a rate determining olefin insertion step, and 3) a $\mathrm{C}-\mathrm{H}$ activation step. Unfortunately, we have been unable to synthesize or isolate the active catalytic species as they are believed to be uphill from the trans ground state and readily collapse back to the trans-R-Ir-L species upon isolation attempts.

An alternative mechanism to $\mathrm{C}-\mathrm{H}$ activation is the alkylation of arenes using Lewis acid catalysts. The (acac- $O, O)_{2} \mathrm{Ir}^{\mathrm{III}}$ complexes are considered "soft" Lewis acids, ${ }^{1}$ especially given the recent precedent for the use of transition metal complexes such as Au, Pt and Pd as general Lewis acids for catalyzing reactions between alkenes/alkynes and arenes. ${ }^{28}$ However, the central observation that the hydroarylation reaction catalyzed by the (acac- $O, O)_{2} \mathrm{Ir}^{\mathrm{III}}$ complexes generate alkylarenes with antiMarkovnikov regioselectivity would tend to rule out mechanisms occurring via carbocation intermediates. Several other observations also have indicated that a carbocation intermediate is likely not involved:

1) Alkylarenes are more reactive than the parent arenes toward alkylation in Lewis acid catalyzed reactions. Alkyl benzenes are less reactive when using $(\text { acac- } O, O)_{2} \operatorname{Ir}(\mathrm{R})(\mathrm{L})$ catalysts. For example, hydroarylation of ethylene with benzene shows approximately double the TON and TOF as compared to ethylbenzene. ${ }^{16 a}$

2) Lewis acid catalyzed reactions are typically inhibited by 1 eq. of water. However, the (acac- $O, O)_{2} \mathrm{Ir}^{\mathrm{III}}$ catalysts are not inhibited by the addition of several equivalents of water. ${ }^{16}$

3) Lewis acids readily catalyze the exchange of alkyl groups between alkylarenes. However, the (acac- $O, O)_{2} \mathrm{Ir}^{\mathrm{III}}$ complexes do not catalyze reactions of diethylbenzene with benzene to generate mono-ethyl benzene under hydroarylation conditions.

4) Reaction rates of Lewis acid catalyzed reactions strongly correlate with the strength of the Lewis acid. However, while $\mathrm{IrCl}_{3}$ could be expected to be a stronger Lewis acid than the (acac- $O, O)_{2} \mathrm{Ir}^{\mathrm{III}}$ complexes, $\mathrm{IrCl}_{3}$ does not catalyze the hydroarylation reaction under identical conditions.

5) The observation that other Ir catalysts show no hydroarylation activity or the same product selectively strongly suggests a unique catalytic activity for the (acac- $O, O)_{2} \mathrm{Ir}^{\mathrm{III}}$ complexes. ${ }^{16}$

As can be seen in Scheme 2, it is proposed that all the various R-Ir-L as well as dinuclear ([R-Ir $\left.]_{2}\right)$ complexes are catalyst precursors that in a series of pre-equilibrium steps (that can involve ligand loss, trans-cis isomerization, arene $\mathrm{C}-\mathrm{H}$ activation and olefin coordination) lead to the same active catalyst, cisPh-Ir-Ol, independent of the starting complex. Mechanisms involving $\mathrm{C}-\mathrm{H}$ activation ${ }^{16}$ and insertion ${ }^{29}$ are typically innersphere reactions and as such require a vacant coordination site on the metal for coordination of the substrate.

The ligand "L" of the O-donor (acac- $O, O)_{2} \operatorname{Ir}(\mathrm{R})(\mathrm{L})$ complexes significantly influences the rate of the catalytic hydroarylation reaction. Strongly donating ligands, such as pyridine severely inhibit the catalysis; whereas, labile ligands, such as $\mathrm{CH}_{3} \mathrm{OH}$ and $\mathrm{H}_{2} \mathrm{O}$, are weaker inhibitors. The TOFs have been correlated to the calculated relative energies of these complexes, and a linear correlation between the relative energy of the ground states and TOFs was found. ${ }^{15}$
We have previously demonstrated that when $\mathrm{L}=$ pyridine, exchange is facile (e.g. exchange of free pyridine with coordinated pyridine between $\mathbf{P h}-\mathbf{I r}-\mathbf{P y}$ and $\mathbf{C H}_{3}-\mathbf{I r}-\mathbf{P y}$ is rapid at room temperature and independent of the concentration of added free pyridine, as expected for a dissociative process in a preequilibrium step). The exchange was also examined with the cis-Ph-Ir-Py complex. Pyridine exchange with cis-Ph-Ir-Py is much slower $\left(160^{\circ} \mathrm{C} v s\right.$. RT) than that of its trans analog, which is consistent with theoretical predictions. ${ }^{11}$

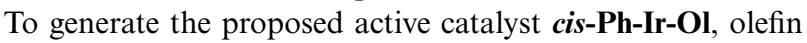
coordination is required. This most likely occurs in a manner similar to conversion of trans-Ph-Ir-Py to cis-Ph-Ir-Py, i.e. by ligand dissociation, cis-trans isomerization and the coordination of the olefin. However, while olefin complexes can be observed by in situ NMR spectroscopy, attempts at generating and isolating such olefin complexes with various trans-R-Ir-L complexes failed, presumably due to instability. NMR analysis showed that addition of ethylene to the dinuclear complex, $[\text { Acac-Ir }]_{2}$, leads to a new mononuclear complex containing coordinated ethylene. However, all attempts at isolating this complex have failed. The instability of the olefin complex(es) is consistent with the lability of the $\mathrm{Py}$ and $\mathrm{H}_{2} \mathrm{O}$ complexes to substitution at room temperature. Ethylene does not coordinate as strongly with (acac- $O, O)_{2} \operatorname{Ir}(\mathrm{R})(\mathrm{L})$ as other $\pi$-acids (such as Py and $\mathrm{CO}$ ), preventing isolation of an olefin complex. Furthermore, our theoretical calculations showed that the five coordinate $\mathbf{c i s - P h -}$ Ir species is higher in energy than the insertion transition state, suggesting that the complex undergoes further reaction under any conditions that allow for its generation. ${ }^{15}$

Since there is rapid scrambling of mixtures of benzene and deuterobenzene (relative to the hydroarylation reaction, see below), a kinetic isotope effect could not be obtained under hydroarylation conditions using mixtures of $\mathrm{C}_{6} \mathrm{H}_{6}$ and $\mathrm{C}_{6} \mathrm{D}_{6}$. However, comparison of the absolute rates of catalytic hydroarylation reactions under the same conditions (styrene and Ph-Ir-Py) in separate experiments with $\mathrm{C}_{6} \mathrm{H}_{6}$ and $\mathrm{C}_{6} \mathrm{D}_{6}$ showed no kinetic isotope effect. This result is not surprising given that olefin insertion is the rate determining step and not $\mathrm{C}-\mathrm{H}$ activation as been shown previously. ${ }^{13}$ Carrying out the catalysis with ethylene and $\mathrm{C}_{6} \mathrm{D}_{6}$ also shows no kinetic isotope effect (KIE), and yields as the major product $\mathrm{C}_{6} \mathrm{D}_{5}-\mathrm{CH}_{2}-\mathrm{CH}_{2} \mathrm{D}$ (as identified by ${ }^{13} \mathrm{C}$ NMR spectroscopy). Under these conditions, only a low level of deuterium is incorporated into unreacted ethylene as seen by GC-MS spectrometry. The possibility of a small secondary KIE is possible; however, we do not see this effect.

Comparative hydroarylation studies between trans-Ph-Ir-Py and cis-Ph-Ir-Py were carried-out at $180{ }^{\circ} \mathrm{C}$, and it was determined that the trans isomer is $4.0 \pm 0.4$ times more active than the cis isomer, cis-Ph-Ir-Py. The TOF of the trans complex decreases over time, most likely because it is converted to the more thermodynamically stable $\mathrm{cis}$ form. However, it is possible that the active catalyst may be generated by loss of the acac ligands. Several observations indicate this is unlikely: 1) the catalyst is long lived (see Fig. 2); 2) the resting state of the catalyst after $>50$ turn-overs (with ethylene) is $\mathbf{P h - I r - P y ; ~} 3$ ) the O-donor (acac- $\mathrm{O}, \mathrm{O})_{2} \mathrm{Ir}^{\mathrm{III}}$ complexes are thermally stable to exchange in the presence of acac- $\mathrm{H}$ and protic acids such as $\mathrm{CH}_{3} \mathrm{CO}_{2} \mathrm{H}$ and $\mathrm{CF}_{3} \mathrm{CO}_{2} \mathrm{H} ;{ }^{16 f}$ 4) trans-Ph-Ir-Py is thermally stable in benzene and 
cleanly undergoes $\mathrm{C}-\mathrm{H}$ activation and olefin insertion reactions to generate alkylarenes. Furthermore, our reported theoretical results showed that loss of an acac group costs $\sim 50 \mathrm{kcal} \mathrm{mol}^{-1}$, i.e. significantly more than the activation energy of the reaction. ${ }^{30}$ These observations strongly suggest that the (acac- $O, O)_{2} \mathrm{Ir}^{\mathrm{III}}$ motif is part of the "active catalyst."

\section{Conclusion}

The O-donor $\mathbf{R}$-Ir-L and $[\mathbf{R}-\mathbf{I r}]_{2}$ complexes are active and stable catalysts for the hydroarylation of unactivated olefins and arenes. This reaction is selective to the linear alkylarenes and generates saturated products only, although it undergoes reversible and unproductive $\beta$-hydrogen elimination as determined by labeling studies. The hydroarylation reactions studied are under kinetic control. The catalyst is a mononuclear species and stable at high temperatures. A key factor is that this reaction leads in one step, directly to alkyl arenes without the production of halogentated waste while avoiding multistep procedures. Mechanistic studies suggest that the mechanism involves pre-equilibrium steps, followed by insertion of olefin, and finally $\mathrm{C}-\mathrm{H}$ activation of benzene to yield the linear alkyl benzene product and regenerate the catalyst.

\section{Experimental Section}

All manipulations were carried out using glovebox and high vacuum line techniques under an inert atmosphere of $\mathrm{N}_{2}$ or argon. Benzene, benzene- $\mathrm{d}_{6}$, toluene- $\mathrm{d}_{8}$ and THF were purified by vacuum transfer from sodium benzophenone ketyl. $\mathrm{CD}_{2} \mathrm{Cl}_{2}$ and pyridine were dried by vacuum transfer from $\mathrm{CaH}_{2}$. Synthetic work involving iridium complexes was carried out in an inert atmosphere in spite of the air stability of the complexes. Reagent-grade chemicals and solvents were used as is and purchased from Aldrich or Strem. $\mathrm{IrCl}_{3} \cdot \mathrm{H}_{2} \mathrm{O}$ was purchased from Strem or Pressure Chemical. $\mathrm{CH}_{3}{ }^{13} \mathrm{CH}_{2} \mathrm{I}$ was purchased from Cambridge Isotopes Inc. and was used as received. Complexes R-Ir-L, $[\mathbf{R}-\mathbf{I r}]_{2}$ and cis-R-Ir-L, ${ }^{14,16,31}$ and diethylmercury ${ }^{32}$ were prepared as described in the literature. Elemental analyses were done by Desert Analytics laboratory (now Columbia Analytical Services), Tucson, Arizona. Liquid phases of the reaction mixtures were analyzed with a Shimadzu GC-MS QP5000 (ver. 2) equipped with cross-linked methyl silicone gum capillary column, DB5. Gas measurements were performed using a GasPro column. The retention times of the products were confirmed by comparison to authentic samples. NMR spectra were obtained on a Bruker AC-250 $(250.134 \mathrm{MHz}$ for ${ }^{1} \mathrm{H}$ and $62.902 \mathrm{MHz}$ for ${ }^{13} \mathrm{C}$ ), Bruker AM-360 $(360.138 \mathrm{MHz}$ for ${ }^{1} \mathrm{H}$ and $90.566 \mathrm{MHz}$ for ${ }^{13} \mathrm{C}$ ), or on a Varian Mercury 400 (400.151 MHz for ${ }^{1} \mathrm{H}$ and $100.631 \mathrm{MHz}$ for ${ }^{13} \mathrm{C}$ ) spectrometer. Chemical shifts are given in ppm relative to TMS or to residual solvent proton resonances. All carbon resonances are singlets unless otherwise mentioned.

Warning! Organomercury compounds are highly toxic! There is a danger of cumulative effects. These compounds may cause serious and irreversible effects on skin contact. These compounds may be fatal if absorbed through the skin - even small amounts, such as a single drop, may cause serious injury or potentially be fatal. They may cause metal fume fever if inhaled or swallowed. Chronic exposure may cause irreversible central nervous system damage, sensitization, weight loss, immunological disease and other serious effects. Work with these dangerously toxic compounds must not begin before a full assessment of the risks have been made and suitable protocols established including reading and understanding available safety information (MSDS) ${ }^{33}$

$\left[\left(\mathrm{CH}_{3}{ }^{13} \mathrm{CH}_{2}\right) \operatorname{Ir}(\boldsymbol{O}, \boldsymbol{O} \text {-acac })_{2}\right]_{2}\left(\left[\mathrm{CH}_{3}{ }^{13} \mathrm{CH}_{2}-\mathrm{Ir}\right]_{2}\right)$. The synthesis was analogous to a previously reported procedure. ${ }^{16} \mathrm{~A}$ flask was loaded with Acac- $\boldsymbol{C}$-Ir- $\mathbf{H}_{2} \mathbf{O}(97 \mathrm{mg}, 0.19 \mathrm{mmol})$ and ${ }^{13} \mathrm{C}$ enriched diethylmercury $(630 \mathrm{mg}, 0.24 \mathrm{mmol})$. The crude reaction mixture was developed on a preparatory silica TLC plate with THF:ether $(1: 1)$ as an eluent and extracted with $\mathrm{CH}_{2} \mathrm{Cl}_{2}$. After pumping off the solvent, the solid was redeveloped on a preparatory silica TLC plate using $1: 1: 2 \mathrm{THF}-\mathrm{CH}_{2} \mathrm{Cl}_{2}$ :hexane. The orange band $R_{\mathrm{f}}=0.87$ was scraped off and extracted with $\mathrm{CH}_{2} \mathrm{Cl}_{2}$ and THF. The solvent was pumped off to yield an orange powder $(0.0410 \mathrm{~g}, 51 \%$ yield $)$. Characterization data matches with a previously reported sample of the non-labeled analog. ${ }^{1} \mathrm{H}$ NMR $\left(\mathrm{CD}_{3} \mathrm{OD}\right): \delta 5.47\left(\mathrm{~s}, 2 \mathrm{H}\right.$, acac-C $\left.{ }^{3} \mathrm{H}\right), 2.83\left(\mathrm{dq},{ }^{1} J_{\mathrm{CH}}=\right.$ $\left.128.5,{ }^{3} J_{\mathrm{HH}}=7.7,-{ }^{13} \mathrm{CH}_{2}-\mathrm{Ir}\right), 1.76\left(\mathrm{~s}, 12 \mathrm{H}\right.$, acac- $\left.\mathrm{CH}_{3}\right), 0.198(\mathrm{~m}$, $\left.3 \mathrm{H}, \mathrm{CH}_{3}{ }^{-13} \mathrm{CH}_{2}-\mathrm{Ir}\right){ }^{13} \mathrm{C}\left\{{ }^{1} \mathrm{H}\right\}$ few scans $\left(\mathrm{CD}_{3} \mathrm{OD}\right): \delta-17.59$ (s, $\left.-{ }^{13} \mathrm{CH}_{2}-\mathrm{Ir}\right)$.

$\left[\operatorname{Ir}(\mathrm{O}, \mathrm{O} \text {-acac })_{2}\left({ }^{13} \mathrm{CH}_{2} \mathrm{CH}_{3}\right)(\mathrm{Py})\right]\left(\mathrm{CH}_{3}{ }^{13} \mathrm{CH}_{2}\right.$-Ir-Py). A flask was loaded with $\left[\mathbf{C H}_{3}{ }^{13} \mathbf{C H}_{2}-\mathbf{I r}\right]_{2}(100 \mathrm{mg}, 0.119 \mathrm{mmol})$ in $\mathrm{CHCl}_{3}$ and pyridine $(1 \mathrm{~mL}, 12.3 \mathrm{mmol})$ following a previously reported prep to give $115 \mathrm{mg}$ (>95\%) of title compound. ${ }^{16}{ }^{1} \mathrm{H}$ NMR $\left(\mathrm{C}_{6} \mathrm{D}_{6}\right): \delta 8.69(\mathrm{~d}, 2 \mathrm{H}$, o-Py), 6.84 (t, 1H, p-Py), $6.56(\mathrm{t}, 2 \mathrm{H}$, $\mathrm{m}-\mathrm{Py}), 5.10\left(\mathrm{~s}, 2 \mathrm{H}\right.$, acac-C $\left.{ }^{3} \mathrm{H}\right), 3.47\left(\mathrm{dq}, 2 \mathrm{H},{ }^{1} J_{\mathrm{CH}}=125.3\right.$, $\left.{ }^{13} \mathrm{CH}_{2}-\mathrm{Ir}\right), 1.60$ (s, $12 \mathrm{H}$, acac- $\left.\mathrm{CH}_{3}\right), 1.23\left(\mathrm{~m}, 3 \mathrm{H}, \mathrm{CH}_{3}{ }^{-13} \mathrm{CH}_{2}-\mathrm{Ir}\right)$. ${ }^{13} \mathrm{C}\left\{{ }^{1} \mathrm{H}\right\}$ NMR $\left(\mathrm{C}_{6} \mathrm{D}_{6}\right): \delta 182.69($ acac $\mathrm{C}=\mathrm{O}), 149.57$ (o-py), 136.32 (p-py), 124.38 ( $m$-py), 102.76 (acac-CH), 26.66 (acac$\left.\mathrm{CH}_{3}\right), 15.99\left(\mathrm{~d},{ }^{1} J_{\mathrm{CC}}=34, \mathrm{CH}_{3}\right),-10.56\left({ }^{13} \mathrm{CH}_{2}-\mathrm{Ir}\right)$.

$\mathrm{Cis}-\left[\mathbf{I r}(\boldsymbol{O}, \boldsymbol{O} \text {-acac })_{2}(\mathbf{P h})(\mathbf{P y})\right]($ cis-Ph-Ir-Py). In addition to the method for the synthesis of cis-Ph-Ir-Py we reported previously, ${ }^{16 a}$ a second route is available. A $5 \mathrm{~mL}$ thick-walled glass tube equipped with a resealable Teflon valve and a magnetic stir bar was charged with $2.5 \mathrm{~mL}$ of benzene containing Ph-Ir-Py $(10 \mathrm{mg}, 0.02 \mathrm{mmol})$. The tube was heated for $100 \mathrm{~h}$ in a wellstirred oil bath maintained at $180^{\circ} \mathrm{C}$. The autoclave was cooled thereafter, and the solvent was removed in vacuo and the solid obtained was washed with cold methanol to yield the complex in $>90 \%$ yield.

Reaction procedure for the olefin arylation. A $3 \mathrm{~mL}$ stainless steel autoclave, equipped with a glass insert, and a magnetic stir bar was charged with $1 \mathrm{~mL}$ of distilled benzene and 3-5 mg ( $5 \mathrm{mmol}, \sim 0.1 \mathrm{~mol} \%$ ) of catalyst (unless otherwise mentioned). The reactor was degassed with nitrogen, pressurized with 0.96 MPa of propylene with an extra $2.96 \mathrm{MPa}$ of nitrogen. The autoclave was heated for $30 \mathrm{~min}$ in a well stirred heating bath maintained at $180{ }^{\circ} \mathrm{C}$. The liquid phase was sampled and the product yields were determined by GC-MS using methyl cyclohexane as an internal standard, which was added after the reaction.

Insertion reactions of olefins with Ph-Ir-Py. A $3 \mathrm{~mL}$ stainless steel autoclave, equipped with a glass insert and a magnetic stir 
bar was charged with $1 \mathrm{~mL}$ of distilled mesitylene and $15 \mathrm{mg}$ of Ph-Ir-Py. The autoclave was heated at $180^{\circ} \mathrm{C}$ for $10 \mathrm{~min}$. after adding the olefin. The liquid phase was sampled and the product yields were determined by GC-MS using methyl cyclohexane as an internal standard, which was added after the reaction. The added amount of olefin is as follows: $2 \mathrm{MPa}$ of ethylene, 0.96 $\mathrm{MPa}$ of propylene with an extra $2 \mathrm{MPa}$ of nitrogen, $0.25 \mathrm{~mL}$ of styrene with $2 \mathrm{MPa}$ of nitrogen and $0.25 \mathrm{~mL}$ of 1 -hexene with 2 $\mathrm{MPa}$ of nitrogen.

Reaction procedure for substrate dependence (olefin). A $10 \mathrm{~mL}$ glass Schlenk flask fitted with a resealable Teflon valve was equipped with a magnetic stir bar and charged with dry, distilled benzene $(1 \mathrm{~mL})$ and $3-5 \mathrm{mg}(5 \mathrm{mmol}, \sim 0.1 \mathrm{~mol} \%)$ of catalyst from a stock solution. To it was added varied amount of styrene (typically 0.1 to $1 \mathrm{~mL}$ ) and $20 \mu \mathrm{L}$ of methylcyclohexane, added as an internal standard. The valve was closed and the flask heated to $180^{\circ} \mathrm{C}$ for $30 \mathrm{~min}$. in a well stirred, temperature controlled oil bath. The liquid phase was sampled and the product yields were determined by GC-MS by comparison to the internal standard.

Reaction procedure for substrate dependence (benzene). A $10 \mathrm{~mL}$ glass Schlenk flask fitted with a resealable Teflon valve and a magnetic stir bar was charged with dry, distilled styrene $(0.6 \mathrm{~mL})$ and $3-5 \mathrm{mg}(5 \mathrm{mmol}, \sim 0.1 \mathrm{~mol} \%)$ of catalyst from a stock solution. Benzene ( 0.1 to $1 \mathrm{~mL})$ and cyclohexane $(0.1$ to $1 \mathrm{~mL}$ ) were added to the flask. An internal standard of $20 \mu \mathrm{L}$ of methylcyclohexane was also added to the flask. The valve was closed and the solution heated to $180{ }^{\circ} \mathrm{C}$ for $30 \mathrm{~min}$. in a well stirred, temperature controlled oil bath. The liquid phase was sampled and the product yields were determined by GC-MS by comparison to the internal standard.

Reaction procedure for catalyst (Ph-Ir-Py) dependence. A $10 \mathrm{~mL}$ glass Schlenk flask fitted with a resealable Teflon valve and a magnetic stir bar was charged with dry, distilled benzene $(1 \mathrm{~mL})$ and styrene $(0.6 \mathrm{~mL})$. Varying amounts of Ph-Ir-Py (2-10 mg) were added as well as 1 eq. of pyridine to each flask. A $20 \mu \mathrm{L}$ aliquot of methylcyclohexane was added as an internal standard. The valve was closed and the solution heated to $180^{\circ} \mathrm{C}$ for $30 \mathrm{~min}$ in a well stirred, temperature controlled oil bath. The liquid phase was sampled and the product yields were determined by GC-MS by comparison to the internal standard.

\section{Computational methodology}

All calculations were performed using the B3LYP hybrid DFT functional as implemented by the Jaguar 7.0 program package. $^{34-36}$ This functional has provided good agreement with experiment for $(\text { acac- } O, O)_{2} \operatorname{Ir}(\mathrm{III})(\mathrm{R})(\mathrm{L})$ complexes and other reaction profiles of transition metal containing compounds. ${ }^{37,38}$ Iridium atoms were described using the Wadt and Hay ${ }^{39}$ corevalence (relativistic) effective core potential in the LACVP basis set for geometry optimizations and single point energies with the LACVP**++ basis set. ${ }^{40,41}$ All energies reported are $\Delta H(298$ $\mathrm{K})=\Delta E+$ zero point energy correction + solvation correction. Relative energies on the $\Delta H(298 \mathrm{~K})$ surface are expected to be accurate to within $3 \mathrm{kcal} \mathrm{mol}^{-1}$ for stable intermediates, and within $5 \mathrm{kcal} \mathrm{mol}^{-1}$ for transition structures. We also note that to be consistent with past computational efforts, the methyl groups on the acac ligands were replaced with hydrogens. ${ }^{11}$

\section{Acknowledgements}

We gratefully acknowledge financial support of this research by the Chevron Corporation, the University of Southern California, The Scripps Research Institute, and the Center for Catalytic Hydrocarbon Functionalization, a DOE Energy Frontier Research Center (DOE DE-SC000-1298) for financial support. We also thank Dr William Schinski for helpful discussions during the preparation of this manuscript.

\section{Notes and references}

1 (a) G. A. Olah, Friedel-Crafts and Related Reactions. Vol. I. General, Aspects.; Vol. II. Alkylation, and Related Reactions. Part 1.; Part 2.; 1964, 1031 pp.; 658 pp.; 703 pp. Wiley-Interscience: New York; (b) K. I. Goldberg and A. S. Goldman, (eds) Activation and Functionalization of $\mathrm{C}-\mathrm{H}$ Bonds ACS Symp. Ser. American Chemical Society: Washington D.C. 2004, 885.

2 (a) M. B. Smith and J. March, March's Advanced Organic Chemistry, 6th ed.; Wiley-InterscienceNew Jersey, 2007, 719-724; (b) N. Isenberg and M. Grdinic, J. Chem. Educ., 1969, 46, 601; (c) M. Grdinic and N. Isenberg, Intra-Sci. Chem. Rep., 1970, 4, 145; (d) For more reviews on Friedel-Crafts chemistry since 2000, please see: M. Rueping and B. J. Nachtsheim, Beilstein J. Org. Chem., 2010, 6, DOI: 10.3762/bjoc.6.6; (e) S. L. You, Q. Cai and M. Zeng, Chem. Soc. Rev., 2009, 38, 2190; (f) T. B. Poulsen and K. A. Jorgensen, Chem. Rev., 2008, 108, 2903; (g) F. Peng and Z. Shao, J. Mol. Catal. A: Chem., 2008, 285, 1; (h) G. Busca, Chem. Rev., 2007, 107, 5366; (i) M. Bandini, A. Melloni and A. Umani-Ronchi, Angew. Chem., Int. Ed., 2004, 43, 550.

3 G. A. Olah and Á. Molnár, Hydrocarbon Chemistry, 2nd ed.; WileyInterscience: New York, 2003; 229-233.

4 We define the $\mathrm{C}-\mathrm{H}$ activation reaction to be a coordination reaction that proceeds without the involvement of free radicals, carbocations, or carbanions to generate discrete M-R intermediates $(a) \mathrm{A}$. E. Shilov and G. B. Shul'pin, Chem. Rev., 1997, 97, 2879; (b) B. A. Arndtsen, R. G. Bergman, T. A. Mobley and T. H. Peterson, Acc. Chem. Res., 1995, 28, 154 and citations therein; (c) R. A. Periana, G. Bhalla, W. J. Tenn, III, K. J. H. Young, X. Y. Liu, O. Mironov, C. Jones and V. R. Ziatdinov, J. Mol. Catal. A: Chem., 2004, 220, 7 and citations therein; (d) B. L. Conley, W. J. Tenn, III, K. J. H. Young, S. K. Ganesh, S. K. Meier, V. R. Ziatdinov, O. Mironov, J. Oxgaard, J. Gonzales, W. A. Goddard, III and R. A. Periana, J. Mol. Catal. A: Chem., 2006, 251, 8; (e) R. H. Crabtree, J. Organomet. Chem., 2004, 689, 4083; ( $f$ ) M. Lersch and M. Tilset, Chem. Rev., 2005, 105, 2471.

5 (a) S. Murai, F. Kakiuchi, S. Sekine, Y. Tanaka, A. Kamatani, M. Sonoda and N. Chatani, Nature, 1993, 366, 529; (b) S. Murai, N. Chatani and F. Kakiuchi, Pure Appl. Chem., 1997, 69, 589; (c) X. Zhang, M. Kanzelberger, T. J. Emge and A. S. Goldman, J. Am. Chem. Soc., 2004, 126, 13192.

6 (a) M. T. Wentzel, V. J. Reddy, T. K. Hyster and C. J. Douglas, Angew. Chem., Int. Ed., 2009, 48, 6121; (b) Y. Kuninobu, T. Matsuki and K. Takai, J. Am. Chem. Soc., 2009, 131, 9914; (c) R.-V. Nguyen, X. Yao and C.-J. Li, Org. Lett., 2006, 8, 11.

7 (a) K. Krogh-Jespersen, M. Czerw, K. Zhu, B. Singh, M. Kanzelberger, N. Darji, P. D. Achord, K. B. Renkema and A. S. Goldman, J. Am. Chem. Soc., 2002, 124, 10797; (b) X. Zhang, M. Kanzelberger, T. J. Emge and A. S. Goldman, J. Am. Chem. Soc., 2004, 126, 13192.

8 (a) H. Harada, R. K. Thalji, R. G. Bergman and J. A. Ellman, J. Org. Chem., 2008, 73, 6772; (b) X. Han and R. A. Widenhoefer, Org. Lett., 2006, 8, 3801; (c) S. W. Youn, S. J. Pastine and D. Sames, Org. Lett., 2004, 6, 581; (d) C. Jia, D. Piao, J. Oyamada, W. Lu, T. Kitamura and Y. Fujiwara, Science, 2000, 287, 1992; (e) N. Marion, S. Diez-Gonzalez, P. de Fremont, A. R. Noble and S. P. Nolan, Angew. Chem., Int. Ed., 2006, 45, 3647; (f) J. R. Chen, C. F. Li, X. L. An, J. J. Zhang, X. Y. Zhu and W. J. Xiao, Angew. Chem., Int. Ed., 2008, 47, 2489; (g) H. H. Lu, H. Liu, W. Wu, X. F. Wang, L. Q. Lu and W. J. Xiao, Chem.-Eur. J., 2009, 15, 2742; (h) T. S. Jian, R. Y. Tang, X. G. Zhang, X. H. Li and L. H. Li, J. Org. Chem., 2009, 74, 8834; (i) C. Jia, T. Kitamura and Y. Fujiwara, Acc. Chem. Res., 2001, 34, 633; (j) C. Nevado and A. M. Echavarren, Synthesis, 2005, 167; (k) I. J. S. Fairlamb, Annu. Rep. Prog. Chem., Sect. B, 2006, 102, 50; 
(l) K. Komeyama, R. Igawa and K. Takaki, Chem. Commun., 2010, 46, 1748; (m) K. Xie, S. Wang, P. Li, X. Li, Z. Yang, X. An, C. C. Guo and Z. Tan, Tetrahedron Lett., 2010, 51, 4466; (n) J. Mo and P. H. Lee, Org. Lett., 2010, 12, 2570.

9 (a) S. I. Kozhushkov, D. S. Yufit and L. Ackermann, Org. Lett., 2008, 10, 3409; (b) C. Jia, T. Kitamura and Y. Fujiwara, Acc. Chem. Res., 2001, 34, 633; (c) R. A. Windenhoefer, Chem.-Eur. J., 2008, 14, 5382; (d) L. A. Goj and T. B. Gunnoe, Curr. Org. Chem., 2005, 9, 671; (e) K. A. Pittard, J. P. Lee, T. R. Cundari, T. B. Gunnoe and J. L. Petersen, Organometallics, 2004, 23, 5514; $(f)$ Y. Xiao, X. Liu and C. Che, J. Organomet. Chem., 2009, 694, 494; $(g)$ K. M. Gligorich, Y. Iwai, S. A. Cummings and M. S. Sigman, Tetrahedron, 2009, 65, 5074; (h) Y. Iwai, K. M. Gligorich and M. S. Sigman, Angew. Chem., Int. Ed., 2008, 47, 3219; (i) M. Wang, M. Wong and C. Che, Chem.Eur. J., 2008, 14, 8353 .

10 (a) R. Martinez, J. P. Genet and S. Darses, Chem. Commun., 2008, 3855; (b) Z. Zhang, X. Wang and R. A. Widenhoefer, Chem. Commun., 2006, 3717; (c) N. A. Foley, J. P. Lee, Z. Ke, T. B. Gunnoe and T. R. Cundari, Acc. Chem. Res., 2009, 42, 585; (d) G. Bhalla, J. Oxgaard, W. A. Goddard, III and R. A. Periana, Organometallics, 2005, 24, 3229.

11 J. Oxgaard, R. A. Periana and W. A. Goddard, III, J. Am. Chem. Soc., 2004, 126, 11658

12 (a) M. Lail, B. N. Arrowood and T. B. Gunnoe, J. Am. Chem. Soc., 2003, 125, 7506; (b) M. Lail, C. M. Bell, D. Conner, T. R. Cundari, T. B. Gunnoe and J. L. Petersen, Organometallics, 2004, 23, 5007; (c) N. A. Foley, M. Lail, J. P. Lee, T. B. Gunnoe, T. R. Cundari and J. L. Petersen, J. Am. Chem. Soc., 2007, 129, 6765.

13 J. Oxgaard, R. P. Muller, W. A. Goddard, III and R. A. Periana, J. Am. Chem. Soc., 2004, 126, 352.

14 T. Matsumoto, D. J. Taube, R. A. Periana, H. Taube and H. Yoshida, J. Am. Chem. Soc., 2000, 122, 7414.

15 J. Oxgaard and W. A. Goddard, III, J. Am. Chem. Soc., 2004, 126, 442.

16 (a) T. Matsumoto, R. A. Periana, D. J. Taube and H. Yoshida, J. Mol. Catal. A: Chem., 2002, 180, 1; (b) T. Matsumoto, R. A. Periana, D. J. Taube and H. Yoshida, J. Catal., 2002, 206, 272; (c) R. A. Periana, X. Y. Liu and G. Bhalla, Chem. Commun., 2002, 3000; (d) A. G. Wong-Foy, G. Bhalla, X. Y. Liu and R. A. Periana, J. Am. Chem. Soc., 2003, 125, 14292; (e) G. Bhalla, X. Y. Liu, J. Oxgaard, W. A. Goddard, III and R. A. Periana, J. Am. Chem. Soc., 2005, 127, 11372; (f) S. M. Bischof, D. H. Ess, S. K. Meier, J. Oxgaard, R. J. Nielsen, G. Bhalla, W. A. Goddard, III and R. A. Periana, Organometallics, 2010, 29, 742.

17 P. J. Chenier, Survey of Industrial Chemistry, 2nd ed.; Wiley-VCH: New York, 1992.

18 X. Y. Liu, W. J. Tenn, III, G. Bhalla and R. A. Periana, Organometallics, 2004, 23, 3584-3586.

19 (a) G. Bhalla and R. A. Periana, Angew. Chem., Int. Ed., 2005, 44, 1540; (b) G. Bhalla, J. Oxgaard, W. A. Goddard, III and R. A. Periana, Organometallics, 2005, 24, 3229.

20 Turnover frequency (TOF) is defined as [ $(\mathrm{mol}$ of product produced $) /(\mathrm{mol}$ of added catalysts)] per second. Turnover number (TON) is defined as $[(\mathrm{mol}$ of product produced $) /(\mathrm{mol}$ of added catalysts)] when the reaction is stopped. Moles of catalyst for the above calculations are based upon moles of added iridium.

21 Reactions were run under pseudo first order conditions with the requirement that $>5 \%$ conversion of starting material must occur, but no more than $10 \%$ of the starting material is converted to product.

22 Chemical reaction software "Outokumpu HSC Chemistry for Windows" ver. 4, Finland.

23 (a) G. T. Crisp, Chem. Soc. Rev., 1998, 27, 427; (b) W. A. Herrmann, V. P. W. Boehm and C. P. Reisinger, J. Organomet. Chem., 1999, 576, 23.

24 G. Bhalla, J. Oxgaard, W. A. Goddard, III and R. A. Periana, Organometallics, 2005, 24, 5499.

25 (a) J. P. Collman, L. S. Hegedus, J. R. Norton and R. G. Finke, Principles and Applications of Organotransition Metal Chemistry, University Science Books: Mill Valley, CA, 1987; (b) J. X. McDermott, J. F. White and G. M. Whitesides, J. Am. Chem. Soc., 1976, 98, 6521; (c) B. J. Burger, M. E. Thompson, W. D. Cotter and J. E. Bercaw, J. Am. Chem. Soc., 1990, 112, 1566.

26 (a) P. Burger and R. G. Bergman, J. Am. Chem. Soc., 1993, 115, 10462; (b) P. O. Stoutland and R. G. Bergman, J. Am. Chem. Soc., 1988, 110, 5732.

27 C. Slugove, I. Padilla-Martinez, S. Sirol and E. Carmona, Coord. Chem. Rev., 2001, 213, 129.

28 (a) D. Karshtedt, A. T. Bell and T. D. Tilley, Organometallics, 2004, 23, 4169; (b) M. S. Viciu, E. D. Stevens, J. L. Petersen and S. P. Nolan, Organometallics, 2004, 23, 3752; (c) S. W. Youn, S. J. Pastine and D. Sames, Org. Lett., 2004, 6, 581.

29 (a) S. Hong and T. J. Marks, Acc. Chem. Res., 2004, 37, 673; (b) M. J. Tanner, M. Brookhart and J. M. DeSimone, J. Am. Chem. Soc., 1997, 119, 7617; (c) X. He and J. F. Hartwig, J. Am. Chem. Soc., 1996, 118, 1696.

30 D. H. Ess, S. M. Bischof, J. Oxgaard, R. A. Periana and W. A. Goddard, III, Organometallics, 2008, 27, 6440.

31 M. A. Bennett and T. R. B. Mitchell, Inorg. Chem., 1976, 15, 2936.

32 H. Gilman and R. E. Brown, J. Am. Chem. Soc., 1929, 51, 928.

33 M. B. Blayney, J. S. Winn and D. W. Nierenberg, Chem. Eng. News, 1997, 75, 7 Available online from the American Chemical Society at http://pubs.acs.org/cen/safety/19970512.html.

34 Jaguar 7.0, Schrodinger, Inc., Portland, Oregon, 2007.

35 A. D. Becke, J. Chem. Phys., 1993, 98, 5648.

36 C. Lee, W. Yang and R. G. Parr, Phys. Rev. B: Condens. Matter, 1988, 37, 785 .

37 J. Baker, M. Muir, J. Andzelm and A. Scheiner, "In Chemical Applications of Density-Functional Theory"; B. B. Laird, R. B. Ross and T. Ziegler, ed.; ACS Symposium Series 629; American Chemical Society: Washington, DC, 1996.

38 S. Niu and B. M. Hall, Chem. Rev., 2000, 100, 353.

39 (a) P. J. Hay and W. R. Wadt, J. Chem. Phys., 1985, 82, 299; (b) W. A Goddard, III, Phys. Rev., 1968, 174, 659; (c) C. F. Melius, B. O. Olafson and W. A. Goddard, III, Chem. Phys. Lett., 1974, 28, 457.

40 Previously, we have examined the effect of basis sets on the calculations for (acac- $O, \mathrm{O})_{2}$ Ir systems. However, it was found that the double-zeta basis set used here correlates with experiment and reduces the computational time relative to larger basis sets. Please see J. Oxgaard, R. A. Periana and W. A. Goddard, III, J. Am. Chem. Soc., 2004, 126, 11658.

41 (a) P. C. Hariharan and J. A. Pople, Chem. Phys. Lett., 1972, 16 217; (b) M. M. Francl, W. J. Pietro, W. J. Hehre, J. S. Binkley, M. S. Gordon, D. J. DeFrees and J. A. Pople, J. Chem. Phys., 1982, 77, 3654. 